\title{
Dynamics versus Thermodynamics: The Sea Ice Thickness Distribution
}

\section{Christian Haas}

\subsection{Introduction}

Changes of sea ice coverage are commonly taken as an indicator for climate change. Since 30 years, the area of the Arctic and Southern oceans covered by sea ice is routinely monitored by satellite radiometers (Chapter 6). These observations show that the ice coverage of the Arctic Ocean strongly declines during summer, with an average rate of $-11.1 \%$ per decade. However, in 2007 and 2008, this trend was drastically exceeded when sea ice extent reduced to record lows of only 4.13 and $4.52 \mathrm{~km}^{2}$, less than $20 \%$ of previous summers, and raising concerns that the Arctic Ocean might become ice-free during summers within the next few decades. However, winter ice coverage of the Arctic Ocean decreases at a much slower pace of only $-2.8 \%$ per decade. And in contrast to the Arctic, sea ice coverage of the Southern Ocean increases slightly, with $0.6 \%$ and $3.4 \%$ per decade in the winter and summer, respectively.

The sea ice decline in the Arctic is much more rapid than predicted by any of the Intergovernmental Panel for Climate Change (IPCC) climate models (Stroeve et al., 2007). This demonstrates our limited understanding of the processes of sea ice growth and melt, and ice motion and deformation. For a full understanding of the areal changes, additional information on ice thickness is required, but is largely missing up to the date of this writing. This chapter will discuss the importance of ice thickness information, the most frequently used ice thickness measurement techniques and results from observations of long-term, interannual and seasonal thickness variations.

In Chapter 2, it was described how sea ice initially forms from open water and subsequently grows into an ice cover, or in other terms, how sea ice grows thermodynamically. One of the basic concepts is that the more the ice grows thicker, the colder the air is due to the establishment of greater temperature gradients in the ice, and higher freezing rates. Vice versa, it would follow that as a consequence of climate warming, the polar sea ice cover would become thinner. However, another process contributes to the sea ice thickness distribution: Due to its relative thinness - some decimetres to a few metres - sea ice floating over deep water is subject to winds and currents which steadily move the ice around, i.e. the ice cover drifts. As a result, it breaks up into floes interspersed by open water leads. With changing drift directions and speeds, the ice floes will be pushed together and collide with each other. If the resulting forces in the ice become too large, it will finally break. The resulting 
ice fragments and blocks will be pushed onto, and below, the edges of the floes forming the so-called pressure ridges (Fig. 4.1).

Obviously, such dynamically formed ridges are much thicker than the adjacent, thermodynamically grown undeformed level ice. In terms of a statistical approach, this discussion shows that it is important to take into account different ice thickness classes (from thin to thick ice), and that a certain mean ice thickness can be attained by many different arrangements of thin and thick ice. As a consequence, it is quite difficult to interpret ice thickness data for indications of climate warming or cooling. This will be illustrated in later sections of this chapter.

Figure 4.2 shows three thickness profiles of ice floes of different developmental stage obtained in the western Weddell Sea, Antarctica: thin first-year ice, thick first-year ice and second-year ice. In general, the figure shows that the ice becomes thicker with increasing age. Not that the thickness of these ice floes is also comparable to typical first- and secondyear thicknesses in the Arctic, which is hardly seen in other regions of the Southern Ocean. However, the figure also demonstrates the increasing degree of deformation and accumulation of deformed ice the ice floes undergo while becoming older. With the thin first-year ice, the original, uniform level ice thickness can well be seen and represents the thermodynamic growth since the first formation of the ice sheet. Ice thicknesses are less uniform with the thicker first-year ice, but the most frequent level ice thickness of $2.5 \mathrm{~m}$ can still be seen. The second-year floe is composed almost exclusively of deformed ice. Note that also snow thickness increases with increasing age of the ice in these Antarctic examples.

The ultimate variable to assess the shrinking or growing of the global sea ice cover is ice volume, i.e. the mathematical product of areal ice coverage and ice thickness. In contrast to ice thickness, sea ice coverage can be monitored reasonably well from space using satellites (Chapter 6). However, from the discussion above, it follows that as long as the ice thickness is unknown, the observed recent changes of ice coverage reported in that chapter are difficult to interpret in terms of overall ice volume and climate signals. These changes are mainly due to a retreat or advance of the ice edge in certain regions. It should be noted, however, that the location of the ice edge is a result of an equilibrium between ice drift, new ice formation and melting, i.e. atmospheric heat flux (including air temperature) and ocean heat flux.

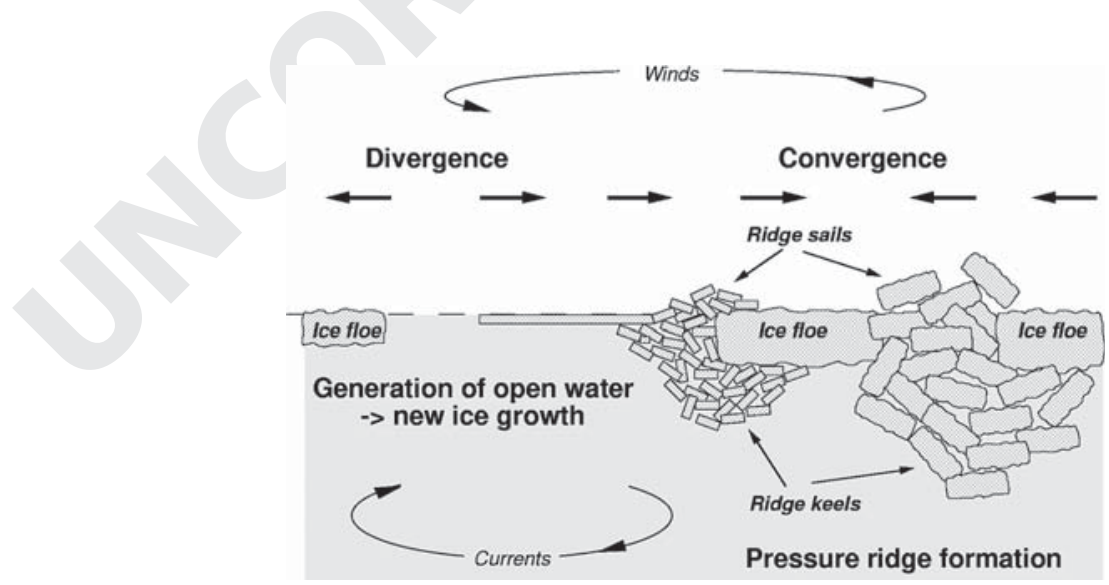

Fig. 4.1 Illustration of the processes that dynamically (i.e. by divergent or convergent ice motion and deformation) modify the ice thickness distribution. 

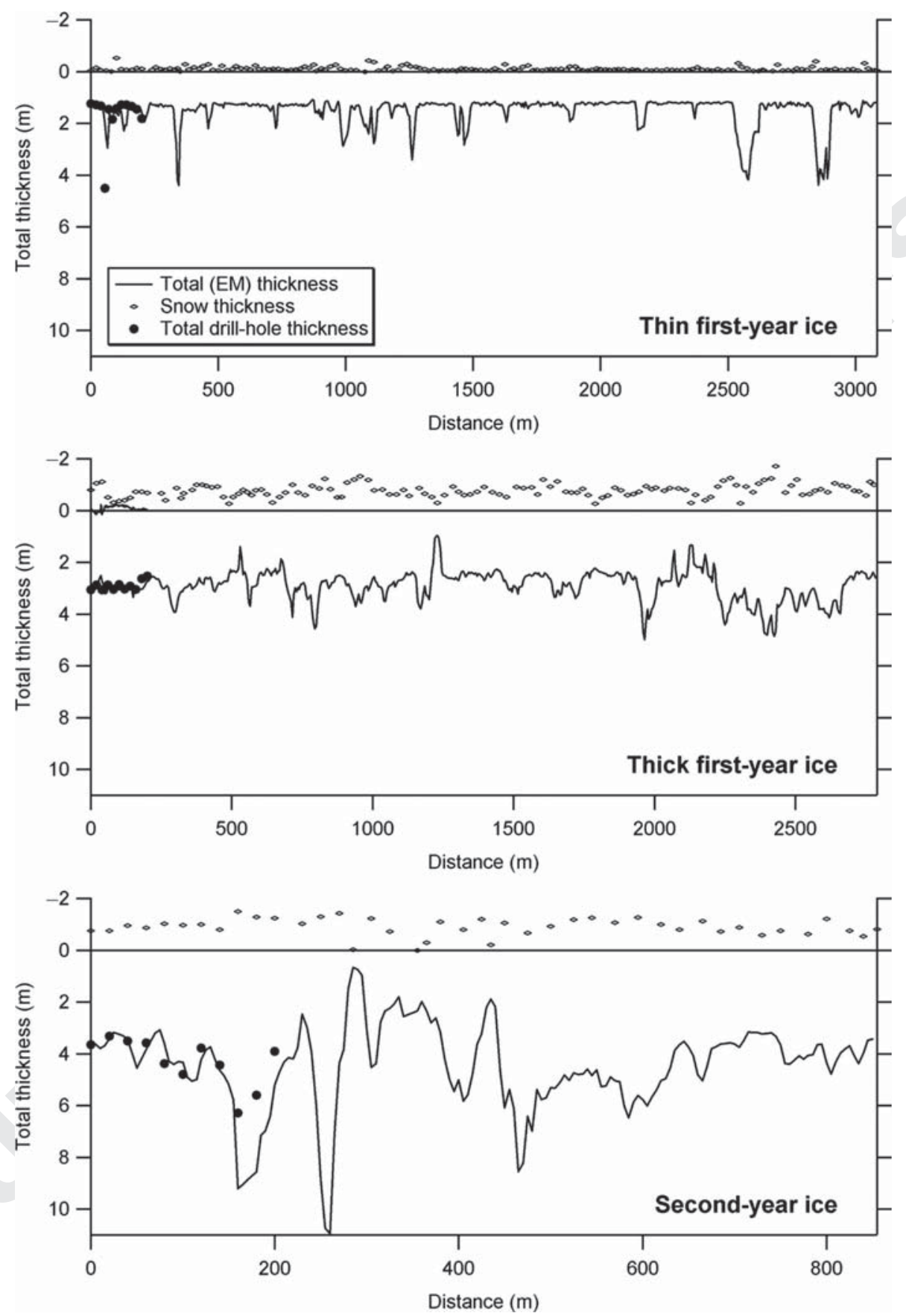

Fig. 4.2 Thickness profiles of (a) thin first-year, (b) thick first-year and (c) second-year ice floes in the Weddell Sea obtained by ground-based EM sounding and drilling. The graphs show total (ice plus snow) thickness plotted downwards from $Z=0$, and snow thickness plotted upwards, to give an approximate representation of the surface and bottom morphology. Note the different horizontal scales and number of measurements shown in each panel. 
Particularly, the latter is a function of the velocity and heat content of ocean currents, whose origin usually is in non-polar latitudes. Prominent examples are the West Spitzbergen and Barents Sea branches of the Norwegian Current, which are the northward extensions of the Gulf Stream. Due to these complexities of the air-ice-ocean system, even the retreat of an ice edge is not necessarily linked to an overall decrease of ice volume.

This chapter presents the physical and statistical approaches used to understand and simulate the ice thickness distribution on a local and regional scale, as well as what is known about the global distribution of ice thicknesses. Different methods to determine ice thickness are presented, as well as some recent results of observations of the variability and trends of sea ice thickness in certain regions.

\subsection{The sea ice thickness distribution}

\section{Statistical description}

Figure 4.3 shows aerial photographs of typical ice regimes of first-year ice in the Weddell Sea, heavily deformed multiyear ice in the Lincoln Sea north of Ellesmere Island, Canada, and second-year ice at the North Pole in summer. The photos show obvious differences of the morphology of the ice. These also represent differences in thickness, as the floating ice is generally in isostatic equilibrium and higher surface elevations indicate regions of deeper drafts and thicker ice. Large level areas of first-year ice (Fig. 4.3a) indicate a uniform thickness distribution, with only few ridges contributing to thicker ice. In contrast, the heavily deformed multiyear ice (Fig. 4.3b) comprises extensive regions of thick pressure ridges. The ice is generally much thicker, but there are also few regions of thinner ice which forms occasionally in leads opening between the thick multiyear ice floes. In contrast, in summer, strong surface melting occurs even at the North Pole, and the ice surface is then extensively covered with melt ponds (Fig. 4.3c). These cause local thinning and therefore contribute to a general roughening of the ice. The modes of second-year thickness distributions (Fig. 4.3c) are therefore often broader than the modes of first-year ice (Fig. 4.3a). When leads open between floes in summer, they do not refreeze for a while, introducing regions with zero ice thickness.

The thickness distribution is defined as a probability density function (PDF) $g(h)$ of the areal fraction of ice with a certain ice thickness in a certain region $R$ (Thorndike et al., 1975). The PDF of ice thickness $g(h)$ is given by:

$$
g(h) \mathrm{d} h=\mathrm{d} A(h, h+\mathrm{d} h) / R
$$

where $\mathrm{d} A(h, b+\mathrm{d} h)$ is the areal fraction of a region $R$ covered with ice of thickness between $h$ and $(b+\mathrm{d} h)$. In practice, the thickness distribution is mostly obtained along linear profiles, and $\mathrm{d} A$ and $R$ are one-dimensional, with $R$ as the total length of the profile. $g(b)$ is derived by dividing a frequency histogram of ice thickness data by the bin-width $(\mathrm{d} h)$. Thus, its dimension is $\mathrm{m}^{-1}$. The advantage of using a PDF instead of a normal frequency distribution is that the numerical value of each thickness bin is independent of the bin-width used in calculating the histogram. This may be required if numerical values of thickness histograms are to be compared with other distributions, or are used to parameterize the thickness distribution in numerical equations for computer models. For most practical applications, it is sufficient to calculate the frequency distribution and to give results in fractions or as percentages. 

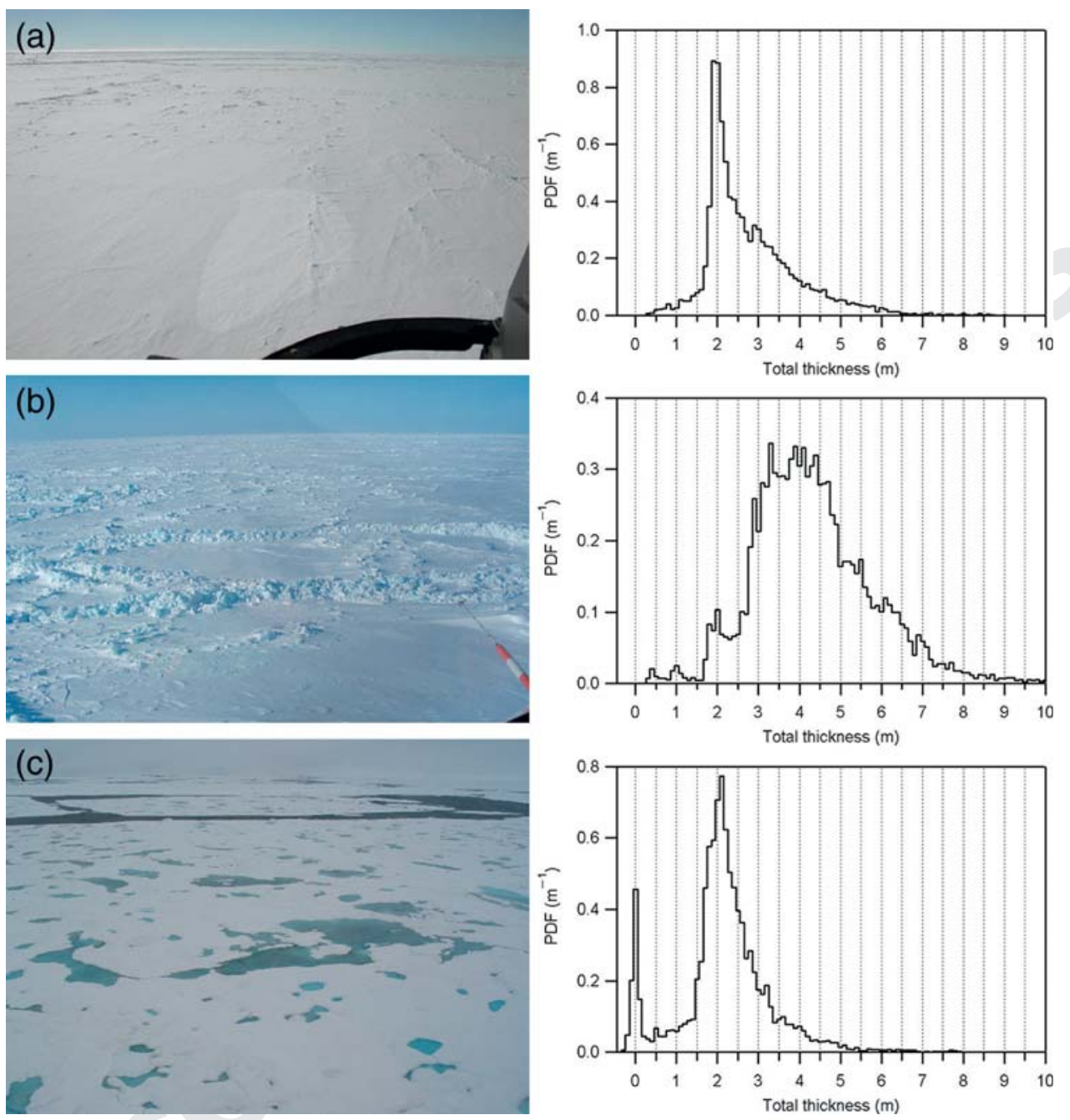

Fig. 4.3 Aerial photographs of typical sea ice types and conditions, and graphs of their corresponding ice thickness distributions (given as probability density functions - PDFs - of total (ice plus snow) thickness): (a) first-year ice in the Weddell Sea, (b) heavily deformed multiyear ice in the Lincoln Sea and (c) second-year ice at the North Pole in summer.

Figure 4.3 also includes the ice thickness distributions of the ice regimes depicted in the aerial photos, typical of ice thickness distributions in general. The distributions are dominated by one or several modes originating from the most frequently occurring thickness classes. Mostly, the modal thicknesses represent the thickness of level ice, as this covers the largest areal fractions of any given sea ice region. The uniformity of the level ice thickness in Fig. 4.3a results in a very narrow, sharp mode of $1.9 \mathrm{~m}$ (Table 4.1). The mixture of floes of different multiyear age accumulated over the years results in blurred modes of between 4.3 and $4.9 \mathrm{~m}$ in the example of Fig. $4.3 \mathrm{~b}$. In addition, newly formed ice in leads and polynyas 
Table 4.1 Mean and modal ice thickness of profiles in Fig. 4.2.

\begin{tabular}{|c|c|c|}
\hline & Mean \pm SD & Mode \\
\hline Fig. 4.2a & $1.5 \pm 0.6 \mathrm{~m}$ & $1.2 \mathrm{~m}$ \\
\hline Fig. $4.2 \mathrm{~b}$ & $2.9 \pm 0.6 \mathrm{~m}$ & $2.5 \mathrm{~m}$ \\
\hline Fig. $4.2 \mathrm{C}$ & $4.4 \pm 1.7 \mathrm{~m}$ & $3.6 \mathrm{~m}$ \\
\hline Fig. 4.3a & $2.8 \pm 1.1 \mathrm{~m}$ & $1.9 \mathrm{~m}$ \\
\hline Fig. 4.3b & $4.3 \pm 1.5 \mathrm{~m}$ & $0.4,1.0,2.0,3.3,3.9 \mathrm{~m}$ \\
\hline Fig. $4.3 \mathrm{C}$ & $2.2 \pm 1.1 \mathrm{~m}$ & $0.0,2.1 \mathrm{~m}$ \\
\hline
\end{tabular}

causes modes at thicknesses of $0.4,1.0$ and $2.0 \mathrm{~m}$. The presence of open water as in Fig. $4.3 \mathrm{c}$ introduces a mode or delta function at a thickness of $h=0.0 \mathrm{~m}$. The long tails of the distributions represent the amount and thickness of pressure ridges. Ice thicker than $6 \mathrm{~m}$ is abundant in the multiyear ice regime of the Lincoln Sea (Fig. 4.3b), while it is almost absent in the younger ice regimes of the Weddell Sea and North Pole (Fig. 4.3a,c). As a consequence, there is quite some difference between the modal and mean thickness of any ice regime, and it is important to consider the kind of thickness value when interpreting the results of thickness observations. Table 4.1 compares modal and mean thicknesses of the thickness profiles shown in Fig. 4.2 and of the thickness distributions shown in Fig. 4.3. Depending on the degree of deformation, pressure ridges can contribute as much as $30-80 \%$ to the total ice volume of a floe or ice field. Therefore, there have been extensive efforts to statistically describe the occurrence and thickness of ridges. After identifying ridges by means of certain criteria from a thickness profile, not only the thickness distributions, but also spacing distributions can be calculated. Interestingly, the tails of both thickness and spacing distributions behave systematically, and can be well described by means of exponential or log-normal functions such as:

$$
n(h)=A \exp (-B h)
$$

where $n(b)$ is the thickness or spacing distribution and $A$ and $B$ are coefficients derived from the mean thicknesses and spacings (Wadhams, 1994). However, it should be noted that there is some dispute as to which statistical function really fits best (Wadhams, 1994). Fortunately, this seems to be of little practical importance.

\section{Modelling changes of the ice thickness distribution}

As mentioned earlier, understanding and predicting the ice thickness distribution requires consideration of both thermodynamic as well as dynamic processes (Fig. 4.1). The temporal development of the ice thickness distribution $\partial g / \partial t$ can be written as (Thorndike et al., 1975):

$$
\partial g / \partial t=-\partial(f g) / \partial h+\operatorname{div}(\nu g)+\Phi
$$

Three terms contribute to this equation (Fig. 4.4): $f(h, x, t)=\mathrm{d} h / \mathrm{d} t$ is the thermodynamic growth or melt rate of ice of thickness $h$ at a location $x$ and time $t . v$ is the ice drift velocity vector, and $\Phi$ is the so-called redistribution function. 


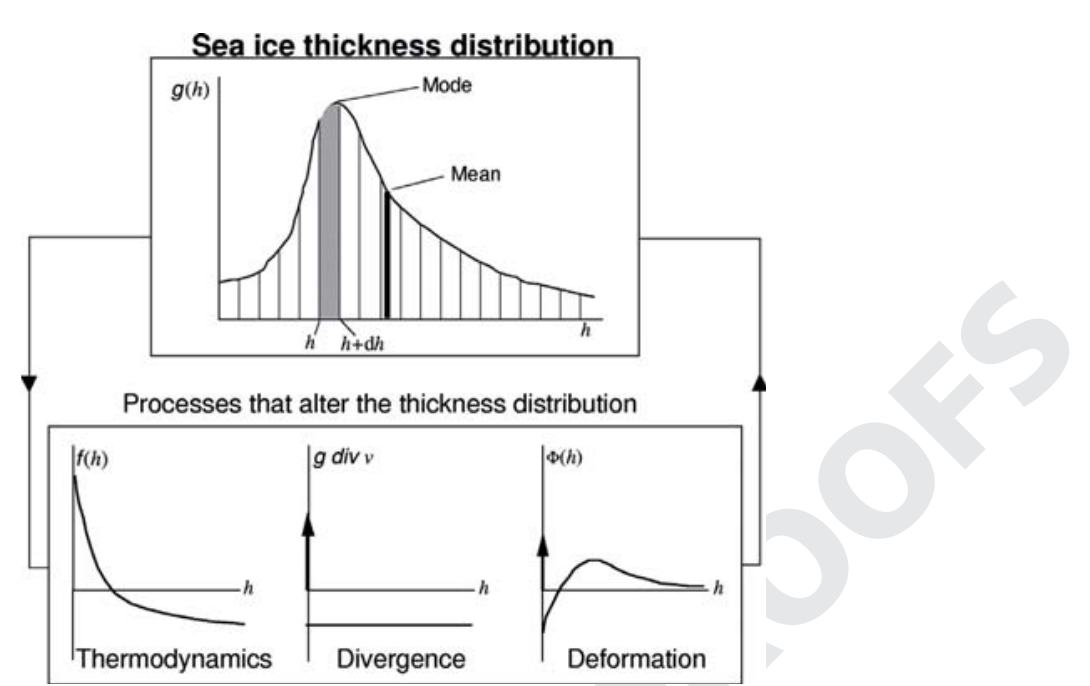

Fig. 4.4 Illustration of the contribution of the different terms and processes in equation 4.1 to the ice thickness distribution.

\section{Thermodynamics}

The thermodynamic growth term of equation 4.1 has been described in detail in Chapter 2 . It should be noted again, however, that it is dependent on ice thickness itself, i.e. that thin ice grows faster than thick ice due to steeper temperature gradients. On the other hand, thermodynamic growth implies that thick ice exceeding a certain equilibrium thickness (e.g. pressure ridges) will melt, even in winter, if the oceanic heat flux exceeds the (generally low) heat flow through thick, insulating ice. The heat conductivity of snow ranges between 0.11 and $0.35 \mathrm{~W} \mathrm{~m}^{-1} \mathrm{~K}^{-1}$ depending on its density and grain structure (see Chapter 5). This is only one-seventh or less of the heat conductivity of sea ice. Therefore, the presence of snow significantly reduces ice growth and the equilibrium ice thickness.

\section{Divergence and advection}

The second term in equation 4.1 represents ice-divergence and advection due to ice motion. As mentioned earlier, the ice is subject to external forces, mainly due to wind and current action (see equation 4.2 below). These forces cause the ice to drift. Away from the coast or other obstacles, the ice will drift freely, and drift direction and speed are closely related to the geostrophic wind. By comparing the motion of drifting buoys deployed on ice floes with geostrophic wind fields, it has been shown that ice in the Arctic drifts at $1 \%$ of the mean wind speed, and with an angle of $18^{\circ}$ to the right (Colony \& Thorndike, 1984; Serreze et al., 1989). For the Weddell Sea, these numbers are $1.6 \%$ and $10-15^{\circ}$ to the left, respectively (Kottmeier et al., 1992).

Divergence within the ice generates cracks, leads, or polynyas with open water where new ice will form. Thus, for a certain region, divergence removes ice of finite thickness and causes a delta signal at zero thickness in the thickness distribution (Fig. 4.4). 


\section{Deformation/convergence}

The last term in equation 4.1 is the redistribution function describing how thin ice is deformed and transformed into thicker ice classes in the case of ice convergence and deformation. It is the most critical term to realistically model the temporal development of the thickness distribution. It is also the most unknown term, since it depends very much on fracture mechanics, and is very dependent on factors like small-scale ice properties, friction between ice blocks among each other as well as at the snow and ice interfaces, and deformation energy and lengths. A very promising approach to ridge formation modelling has been presented by Hopkins (1994) using a dynamic ridge growth model, where the fate of single ice blocks was computed as a function of external forces. However, thin ice will generally deform more easily than thick ice.

On a regional scale, the large-scale spatial thickness distribution is obtained by solving a momentum balance equation considering the main forces acting on a unit area of the sea ice cover:

$$
\mathrm{M} a=\tau_{a}+\tau_{w}+F_{\mathrm{C}}+F_{\mathrm{i}}+F_{\mathrm{t}},
$$

(Equation 4.2)

where the force of mass $M$ times the acceleration $a$ balances the sum of the air and water drags $\tau_{a}$ and $\tau_{w}$, the Coriolis force $F_{C}$, internal ice forces $F_{i}$ and of the force due to sea surface tilt $F_{t}$. Usually, the first two terms are most dominant by more than an order of magnitude. For every model grid cell, mean ice thickness is derived by solving equation 4.2 for ice motion, and distributing the ice volume drifted into a cell equally over the cell area assuming mass conservation. Clearly, as with the redistribution term in equation 4.1, ice strength and rheology are of great importance here. The first models involving plastic or viscous-plastic rheologies were developed by Hibler (1979) and Coon (1980). The rheology describes a viscous flow of an ice field, with plastic deformation once ice concentration and internal ice forces exceed a certain threshold. While these first models prescribed the atmospheric and oceanic forces acting on the ice, today complex coupled atmosphere-ice-ocean models exist (Zhang et al., 2000; Timmermann et al., 2002; Köberle and Gerdes, 2003; Rinke et al., 2003; Gerdes and Köberle, 2007; Holland et al., 2006).

\section{Melting}

Melting commences once the surface energy budget becomes positive. The excess energy is consumed by the latent heat of fusion needed for melting (Chapter 2). Thus, the thermodynamic term in equation 4.1 (thickness balance) just becomes negative. A meteorological consequence is, e.g., that even in summer, air temperatures hardly become positive over ice surfaces.

On large scales, melting patterns correspond to large-scale meteorological conditions and to ocean heat flux regimes. However, even more than with freezing (see above), on small scales melt rates depend critically on the ice thickness distribution itself, and are different for different thickness classes and ice types (Perovich et al., 2003). The heat flux through pressure ridges is lower than through level ice because of their greater thickness. Consequently, they would melt faster. As their keels protrude far down into the water, they might even reach into warmer water. More importantly, ridge keels contribute to the roughness of the 
ice underside, thereby increasing upward turbulent fluxes of heat. The flanks of ridge sails are exposed more normally to the incident solar radiation than ridge crests, as solar elevation is low in polar regions. Therefore, melting can be expected to be higher on the flanks. Although the variations of melt rates might seem to be rather small, they can contribute to significantly different thickness changes in the course of the ablation season.

Much stronger differences in melt rates exist on small thickness classes, i.e. on level ice (Perovich et al., 2003; Eicken et al., 2004). Snow and ice melt water primarily accumulates at topographic low points to form melt ponds. Even small amounts of snow wetting, and the formation of melt ponds, significantly reduce surface albedo. Typical surface albedos are 0.8 for snow, 0.6 for bare ice and $0.15-0.3$ for melt ponds. Thus, once formed, melt ponds absorb more energy than the neighbouring snow or bare ice, thereby increasing local melt rates. Throughout the summer, the surface of melt ponds falls down to sea level, and vertical pond walls form reaching deep into the floe. This positive feedback causes significant changes to the ice thickness distribution of level ice, as it contributes to an increase in surface roughness. This is also demonstrated in the thickness distribution shown in Fig. 4.3c, where melt ponding has caused a roughening of the ice and led to a widening of the dominant mode of the distribution.

The discussion in this section shows that many factors are responsible for shaping the ice thickness distribution. Thinning, for instance, can result from melting, but also from advection of thinner ice into a certain region. Therefore, any interpretation or forecast of changes of the ice thickness distribution in terms of climate change has to take into account both thermodynamic and dynamic processes. This will be highlighted later with the discussion of observations of seasonal, interannual and decadal variations (Section 4.4).

\section{Global sea ice thickness distributions}

Figure 4.5 shows maps of mean ice drift and thickness in the Arctic and Southern oceans, as derived from two coupled ice-ocean models operated at the Alfred Wegener Institute (North Atlantic Ocean Sea Ice Model [NAOSIM], Köberle \& Gerdes, 2003; and the Bremerhaven Regional Ice-Ocean Simulations [BRIOS], Timmermann et al., 2002). Both models have a three-dimensional multilayer ocean model coupled to a dynamic-thermodynamic sea ice model with a viscous-plastic rheology (Hibler, 1979; see above).

It becomes immediately obvious that Arctic sea ice is generally thicker than its counterpart in the Southern Ocean. In the model simulations, most Arctic ice is thicker than $2 \mathrm{~m}$. In contrast, hardly any ice grows as thick in the Southern Ocean. These hemispheric contrasts are due to at least five main differences in the thermodynamic and dynamic boundary conditions of ice growth in the Arctic and Southern oceans:

(1) Ocean heat flux: One fundamental difference between the Arctic and Southern oceans is the occurrence of a fresh mixed layer in the Arctic overlying a strong pycnocline. This layer is fed by the inflow of freshwater from large rivers, mainly from the Siberian continent. The Arctic Ocean receives approximately 10\% of the world river run-off. The fresh mixed layer is very stable and prohibits any significant heat fluxes from the much warmer Atlantic water underneath. A typical value for the ocean heat flux in the Arctic Ocean is $4 \mathrm{~W} \mathrm{~m}^{-2}$. The 'Atlantic layer' at a depth of $200-300 \mathrm{~m}$ is $1-2^{\circ} \mathrm{C}$ warm. 

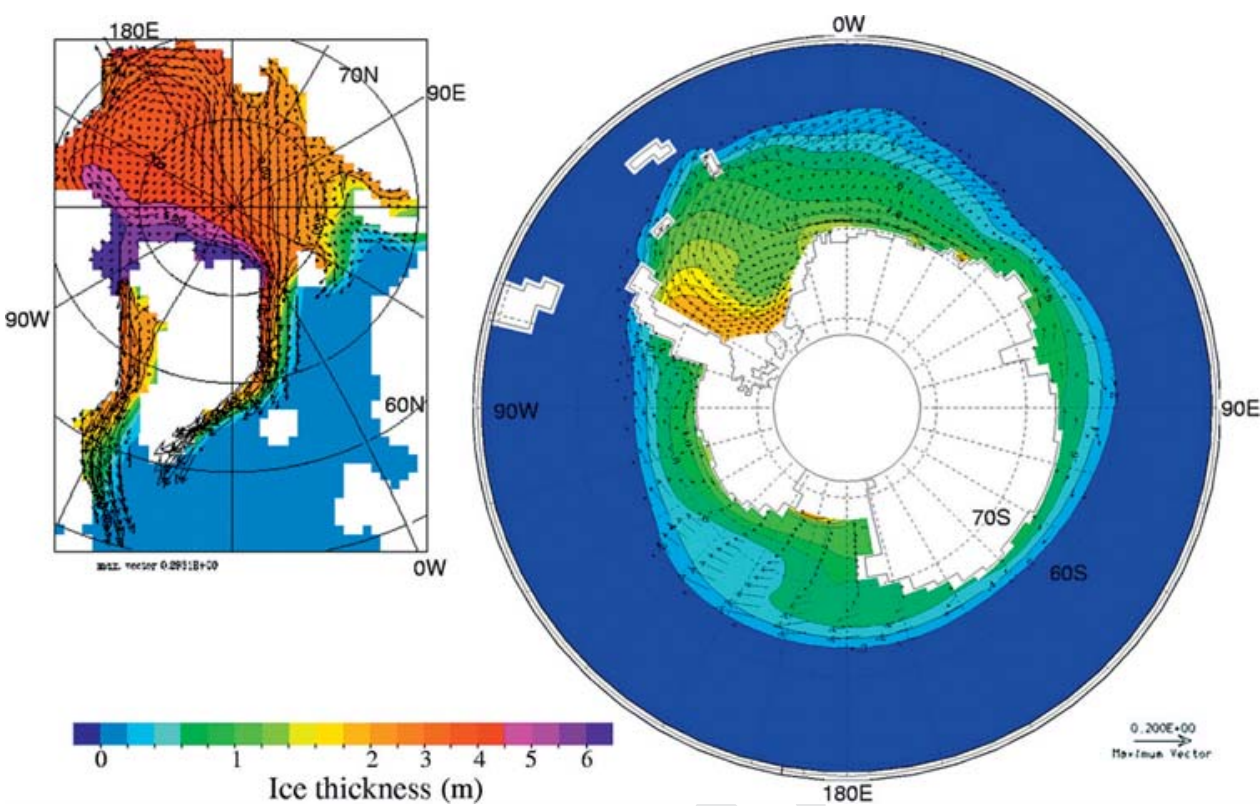

Fig. 4.5 Maps of the Arctic and Southern oceans, showing model results of mean ice drift speed and direction (vectors) as well as mean ice thickness (colours), calculated for the winters of 1985-93. (a) Köberle \& Gerdes (2003). (b) Timmermann et al. (2002). Note that the thickness intervals are irregular.

This heat would be sufficient to melt all ice during summer (Barry et al., 1993). In the Southern Ocean, no rivers enter the seas. Therefore, the mixed layer is much saltier and not well stratified. Mean ocean heat fluxes amount to about $40 \mathrm{~W} \mathrm{~m}^{-2}$.

(2) Snow thickness: With a thermal conductivity between 0.11 and $0.35 \mathrm{~W} \mathrm{~m}^{-1} \mathrm{~K}^{-1}$ (Massom et al., 2001), snow is a strong thermal insulator. Therefore, ice with a thick snow cover grows slower than if the snow were thin. The Arctic Ocean is surrounded by large continents and mean snow thickness reaches only about $0.3 \mathrm{~m}$ in spring (Warren et al., 1999). In contrast, Antarctic sea ice is usually covered by thick snow. On perennial ice in the Pacific sector or in the western Weddell Sea mean snow thickness can be larger than $0.5 \mathrm{~m}$ (Massom et al., 2001). This is due to the fact that the sea ice areas are completely surrounded by oceans, which provide a permanent moisture source. In the South, sea ice may collect the snow blown off the continental ice shelves. As a consequence of the thick snow and high ocean heat fluxes, Antarctic ice may melt at its underside even during winter, because the temperature gradients through the ice are only small.

(3) Ice age: Most ice in the Arctic Ocean drifts for 3-6 years (Colony \& Thorndike, 1984) until it leaves the Basin through the Fram Strait where it melts further south. The older an ice field becomes, the more deformation events it will experience, where it thickens by the accumulation of pressure ridges. This dynamic thickening is accompanied by passing through several winters where the ice can also thicken by thermodynamic growth until it reaches an equilibrium thickness. In contrast, most Antarctic ice melts during summer. Thus, it rarely becomes older than 1 year, and only few regions with 
perennial ice exist in the western Weddell Sea and southern Bellingshausen, Amundsen and Ross Seas.

(4) Divergence versus convergence: As mentioned above, the Arctic Ocean is surrounded by continents, and thus ice motion is confined by coasts where the ice converges and thickens by deformation. In contrast, ice drift around Antarctica is mostly divergent (Kottmeier et al., 1992), with a northerly drift component towards the surrounding open oceans. Divergence causes the opening of polynyas and leads, and the addition of thin new ice to the thickness distribution.

(5) Latitude: Most of the ice in the Arctic is at latitudes north of $70^{\circ} \mathrm{N}$, whereas in the southern hemisphere most ice extends into much lower latitudes, as far north as $55^{\circ} \mathrm{S}$. Thus, air temperatures, total incoming solar radiation and the length of the summer season are generally lower in the Arctic than in the Southern Ocean. However, the Antarctic ice sheet is a giant cold reservoir, and the sea ice region is well isolated from lower latitudes by the atmospheric and oceanic flow regimes of the Circumantarctic Current so that warm and moist air advection are not as important as they are for the Arctic. Due to these, strong surface melting rarely occurs on sea ice in the Southern Ocean (Nicolaus et al., 2006). This is in stark contrast to conditions in the Arctic, where strong surface melting occurs in summer even at the North Pole at much higher latitudes than in the Antarctic.

The order of these points is arbitrary and does not include any ranking between the most important and less important factors. The final ice thickness depends on the magnitude of, and interrelation between, these different aspects. Clearly, both dynamic and thermodynamic factors are responsible for the hemispheric differences.

The maps in Fig. 4.5 also show large regional thickness variations within each hemisphere itself. These are primarily a result of ice motion and deformation. As between $30 \%$ and $80 \%$ of the volume of an ice field is contained within pressure ridges, the mean thickness of a region is more dependent on the number and thickness of ridges than on the thickness of level ice. In other words, for the overall ice volume within a certain region, dynamics is more important than thermodynamics. Therefore, on a regional scale, the average ice thickness distribution is determined by the prevailing atmospheric circulation regimes, which are responsible for mean ice motion and the dominant drift directions. Where the ice drifts against, or shears along a coast, there will be strong ice pressure, and the ice will become heavily deformed. As a result, the mean thickness in regions with mean drift convergence is larger than in regions with mean divergence, where thin new ice is permanently generated and exported.

The arrows in Fig. 4.5 show the dominant drift patterns which develop as the result of the prevailing atmospheric circulation. Although the ice motion is presented only for winter in the figure, this is also representative for the average annual conditions. In the Arctic, mainly two drift systems exist. The Beaufort Gyre is an anticyclonic gyre in the Canada Basin north of the Canadian Archipelago and Alaska. It is caused by quasi-permanent high-atmospheric pressure over the Beaufort Sea. The Beaufort Gyre can transport ice floes for a couple of years before they are exported into the Transpolar Drift. This is the other prominent drift system, which transports ice from the source regions on the Siberian Shelves within about 2-3 years across the North Pole into the Fram Strait and the East Greenland Current, where it finally melts. The Transpolar Drift is mainly driven by low-pressure systems passing from the North Atlantic into the Barents and Kara Seas. 

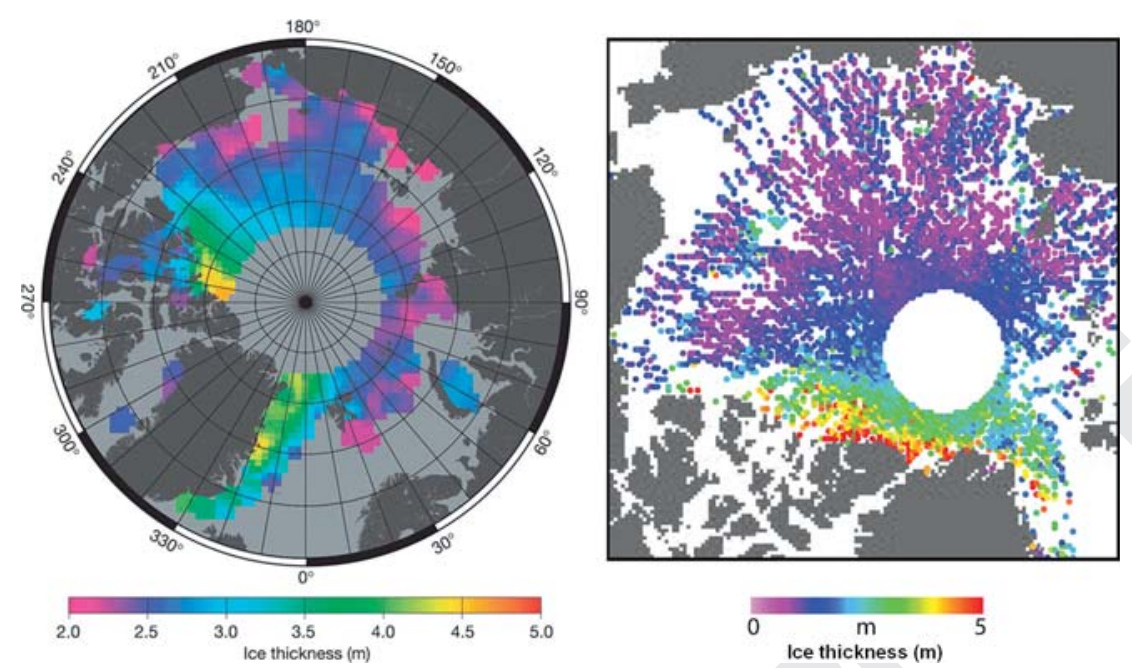

Fig. 4.6 Arctic sea ice thickness maps derived from satellite altimetry. Left: Average October-March ice thickness for the period 1993-2001 obtained from ERS radar altimetry (Laxon et al., 2003). Right: Mean ice thickness in October and November 2006 from ICESat laser altimetry (Kwok and Cunningham, 2008). See Section 4.3 for description of methods.

On average, these drift patterns push the ice against the coasts of northern Greenland and the Canadian Archipelago. Consequently, as a result of strong convergence and deformation, the thickest ice is found in these regions. Mean maximum thicknesses range between 6 and $8 \mathrm{~m}$, mainly resulting from the large spatial density of ridges. Another region with predominantly convergent conditions can be seen in the East Siberian and Chukchi Seas. If the Beaufort Gyre is very strongly developed, ice is pushed against the coast of the New Siberian Islands.

The youngest and thinnest ice is found along the Siberian Shelf, where prominent polynyas occur and from where ice is permanently exported into the Transpolar Drift. The modelled basin-scale thickness distribution is in general agreement with submarine sonar measurements collected over many years over most of the Arctic Ocean (Bourke \& Garret, 1987). It is also well represented in recent thickness maps derived from satellite altimetry (Fig. 4.6, see Section 4.3 for a description of methods).

Figure 4.5 shows that the thickest ice in Antarctica occurs close to the continent, in accordance with the greatest latitude and with the vicinity to the coast where it is sporadically compressed. The most prominent feature, however, is the thickest ice in the southern and western Weddell Sea. On the one hand, this is one of a few regions possessing perennial ice. On the other hand, it is a region where ice drift is directed towards the coast, and subsequently much deformation occurs. The so-called Weddell Gyre is caused by low average sea level pressure over the central Weddell Sea. It should be noted that both the Beaufort Gyre and the Weddell Gyre rotate clockwise. However, due to the Coriolis force, this results in ice convergence within the gyre centre on the northern hemisphere, whereas clockwise circulation results in net divergence inside the gyre in the south. The great thickness in the western Weddell Sea is therefore caused by ice motion away from the divergent gyre centre, with the Antarctic Peninsula acting as an obstacle for the ice drift. 

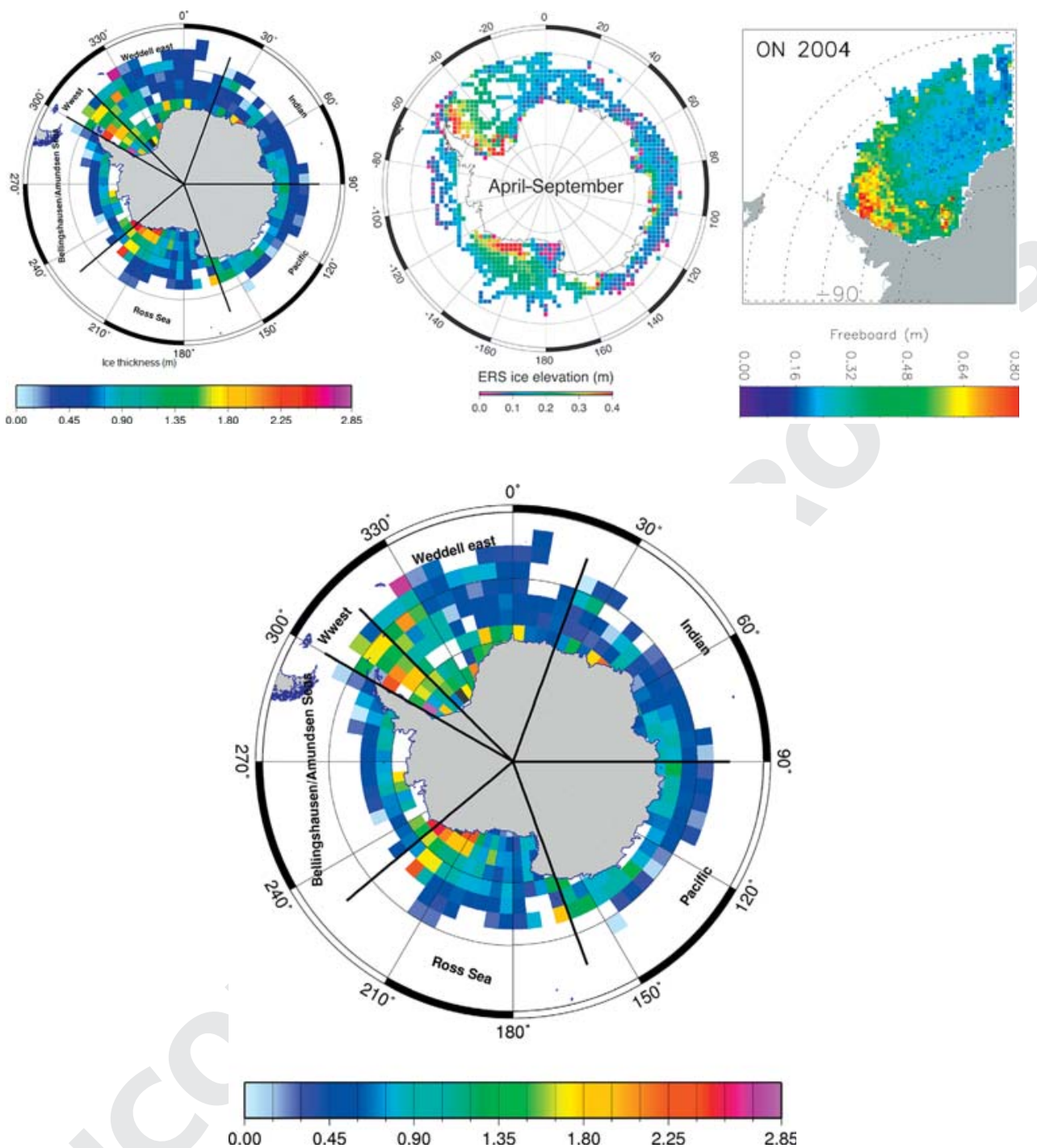

Fig. 4.7 Antarctic sea ice thickness maps derived from visual observations and satellite altimetry. Left: Mean ice thickness from ship-based visual observations performed between 1981 and 2005 (Worby et al., 2008). Centre: Mean ice freeboard measured by ERS radar altimetry between April and September 1995-2002 (Giles et al., 2008). Right: Mean snow freeboard observed by ICESat laser altimetry in October and November 2004. From Zwally et al. (2008).

In contrast to the Arctic, regional ice thickness distributions in the Antarctic are less well known, because only few systematic measurements have been performed. The use of military nuclear submarines is prohibited by the Antarctic Treaty. However, thickness maps derived from visual observations and satellite altimetry show similar patterns (Fig. 4.7) as those computed by the model.

It should be noted that the drift systems and thickness distributions shown in Fig. 4.5 represent long-term average conditions. There is large seasonal, interannual and decadal 
variability superimposed on these mean patterns, which is also obvious by comparisons with the satellite data in Figs. 4.6 and 4.7, and which will be highlighted later in Section 4.4.

\subsection{Measurement techniques}

While extent and concentration of sea ice can be measured with sufficient accuracy by satellites from space, determining its thickness is much more involved, even from aircraft or while standing on the ice. This is due to its relative thinness, which is a challenge for any geophysical measurement technique. Therefore, most methods are indirect measurements, which derive thickness from a related variable which is actually measured instead.

The traditional direct method of ice thickness measurement is to drill a hole into the ice by hand or with a gas- or battery-driven motor. The thickness is measured with a ruler lowered into the hole. This technique is described in detail by Haas \& Druckenmiller (2009). It is also the only method allowing determination of the thickness of the ice and snow, as well as ice draft and freeboard (the depth of the ice underside below the water level and the height of the snow/ice-interface above the water level, respectively) with one measurement and at the same time. Although drilling is tedious, and only limited data can be gathered in a short time, most thickness information about the relatively thin Antarctic sea ice still comes from drill-hole measurements (Lange \& Eicken, 1991; Worby et al., 1996). Only recently have moored upward looking sonars (ULS) and electromagnetic (EM) methods as well as satellite altimetry (see below) been applied in Antarctica.

There are also a number of studies involving video recording of ice floes broken by an icebreaker. The broken ice fragments are often moved side-up against the ship's hull, revealing their cross profile. From the video footage, the thickness can then be manually retrieved. Some studies have shown reasonable agreement of level ice thickness estimates compared with data derived from other methods (Lensu \& Haas, 1998). Similarly, ice thickness can be determined just visually while ice breaking. A coordinated, systematic collection of visual ice observations has been collected by the international Antarctic Sea Ice Processes and Climate (ASPeCt) program and has been compiled by Worby et al. (2008).

Other direct thickness measurements would be pulse radar or ultrasonic sounding where the travel time of a signal through the ice is measured. For sufficient resolution and accuracy, the small thickness requires short radar or sound wavelengths of only some decimetres. However, these high-frequency signals suffer from the heterogeneity of sea ice due to salt inclusions, fractures and rafted ice blocks. These lead to strong signal scatter on the one hand, and to highly variable signal propagation velocities, which must be known to calculate thickness from travel time. Recent new technology developments have led to the design of broadband, continuous-wave frequency-modulated (CWFM) radars for snow and ice thickness measurements, which may improve some of the issues related to absorption and resolution (Kanagaratnam et al., 2007; Holt et al., 2008).

The following sections provide short overviews of the methods most commonly applied today, and which have resulted in the most abundant thickness data so far. More detailed descriptions of these and other techniques including data examples are given by Haas and Druckenmiller (2009). 


\section{Submarine and moored ULSS}

So far, most thickness data have been obtained by means of ULSs or ice profiling sonars (IPS) mounted either on military nuclear submarines (Bourke \& Garret, 1987; Rothrock et al., 1999; Wadhams \& Davis, 2000; Rothrock et al., 2008) or on oceanographic moorings (Strass \& Fahrbach, 1998; Vinje et al., 1998; Harms et al., 2001, Melling \& Riedel, 2004; Melling et al., 2005). With this method, estimates of draft are obtained, i.e. of the depth of the ice underside below the water level, which is a reasonable proxy for ice thickness. The instruments measure the travel time, $t$, of a sonar pulse transmitted by the ULS and reflected back from the ice bottom (Fig. 4.8). Additionally, the depth of the sonar beneath the water level, $z$, and the sound velocity, $v$, in the water must be known. Then, ice draft, $d$, is calculated according to

$$
d=z-v * t / 2
$$

The depth of the ULS is derived from pressure sensors, whose signals are also dependent on air pressure. The sound velocity profile is either assumed constant with a certain sound speed or taken from a mixed layer model (Strass \& Fahrbach, 1998). This can become quite complicated in the case of strong water stratification or when the measurements are

\section{Moored ULS}

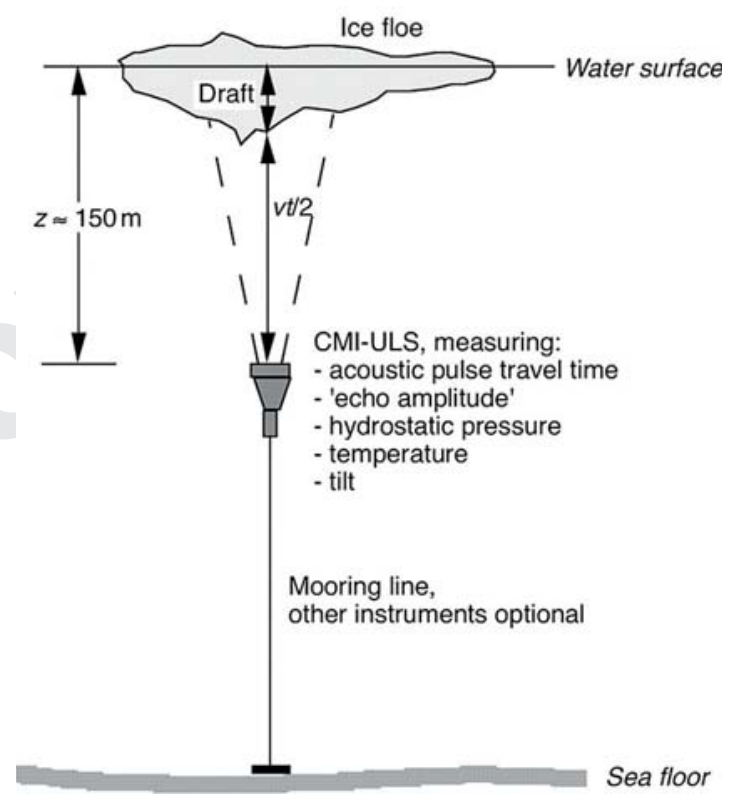

Fig. 4.8 Illustration of ULS ice thickness measurements from an oceanographic mooring. Adapted from Strass and Fahrbach (1998) 
performed close to ocean frontal zones. A plausibility test for the depth measurement or the sound velocity profile can be performed when profiling open leads with ice thickness zero. Then, the measured sonar distance must equal the ULS depth.

Ice thickness, $h$, is calculated from draft, $d$, by assuming isostatic equilibrium, a certain snow depth, $z_{s}$, and water, ice and snow densities $\rho_{w}, \rho_{i}$ and $\rho_{s}$ :

$$
\mathrm{h}=\left(\rho_{w} d-\rho_{s} z_{s}\right) / \rho_{i}
$$

The values for ice and snow density, as well as snow depth, are reasonably well known so that only small errors arise for $h$.

Due to the problems of assuming the correct sound velocity profiles and ULS depth, estimates of the accuracy of absolute level ice thickness measurements range between $0.05 \mathrm{~m}$ (Strass \& Fahrbach, 1998) and 0.25 m (Rothrock \& Wensnahan, 2007). However, an ULS is very sensitive to pressure ridge keels, and their depth relative to the level ice bottom can be very well determined.

Submarines allow for long-range, basin-scale transects for determining the ice thickness profile. However, so far, submarine surveys have only been performed in conjunction with military cruises. This means they provide only snapshots of the ice thickness distribution, because the transects are not performed in a systematic manner. As a consequence, measurements often have to be corrected for seasonal variability before they can be compared with each other (Rothrock et al., 2008). Some improvement was achieved with the SCICEX missions, the Scientific Ice Expeditions of the US navy between 1995 and 1999. These cruises were dedicated to meeting scientific goals, and a small number of scientists were allowed onboard the submarines. Meanwhile, Autonomous Underwater Vehicles (AUVs) are being developed, and they may provide an alternative for the use of submarines in the near future (Wadhams et al., 2006; Dowdeswell et al., 2008). They can also be used in Antarctica, where the operation of military, nuclear submarines is prohibited by the Antarctic Treaty.

ULSs mounted on oceanographic moorings provide long time series of ice thickness in a single location. These allow studying the temporal development of the ice thickness distribution, e.g. in the course of the growing season (Melling \& Riedel, 2004). Transects can be achieved if several moorings are simultaneously operated across a certain region, as current arrays in Fram Strait (Vinje et al., 1998) or the Weddell Sea (Strass \& Fahrbach, 1998; Harms et al., 2001). The thickness distribution between single moorings can then be interpolated. Combined with ice drift velocity data retrieved from satellite imagery or buoys, mooring data allow for the calculation of ice volume fluxes, $Q$, according to:

$$
Q=v b
$$

where $v$ is ice velocity and $b$ is ice thickness.

While moored ULS can provide very valuable continuous data, the operation of the instruments at water depths of 50-150 m for periods of one, or more, years is still a technological challenge. Similarly, the recovery of the instruments is often difficult, or instruments may be lost, e.g. as a result of commercial trawl fishing. Therefore, the success rate of moored ULS measurements is only about $70 \%$. Moorings cannot be deployed in shallow waters, where they might be destroyed by ridge keels or icebergs. 


\section{Electromagnetic induction sounding}

In contrast to high-frequency EM techniques employing radar frequencies, low-frequency, frequency-domain electromagnetic induction (EMI) sounding has become a widely applied method. Typical operating frequencies are between 10 and $100 \mathrm{kHz}$. The technique is usually employed in geophysical problems related to the mapping of ore or groundwater deposits on land. With EM sounding, the mean or apparent electrical underground conductivity is determined. Sea ice is almost an electrical insulator with low electrical conductivities between 0 and $50 \mathrm{mS} \mathrm{m} \mathrm{m}^{-1}$ (milli-siemens per metre). In contrast, cold sea water with a salinity of 32 has a conductivity of $2500 \mathrm{mS} \mathrm{m}^{-1}$. Consequently, the apparent conductivity of the underground decreases with increasing ice thickness, i.e. the more ice occupies the half-space underneath the EM instrument.

The subsurface apparent conductivity is measured by means of two coils, one transmitter and one receiver coil (Fig. 4.9). The transmitter generates a primary EM field which induces eddy currents in the underground. As induction is dependent on the conductivity of the material, the field penetrates through the sea ice almost unaffectedly, and eddy currents are mainly induced in the sea water just below the ice bottom. These eddy currents in turn generate a secondary EM field, whose amplitude and phase are measured with the receiver coil. The secondary field amplitude and phase are primarily dependent on the distance between the eddy currents at the water surface and the coils. This distance is equivalent to ice thickness, if the instrument is lying on the ice. Apparent conductivity is calculated from the imaginary part of the secondary field. Comparison with drill-hole measurements yielded the empirical equation:

$$
h=7.81-1.09 \ln \left(\sigma_{\mathrm{a}}-62.5\right)
$$

(Equation 4.4)
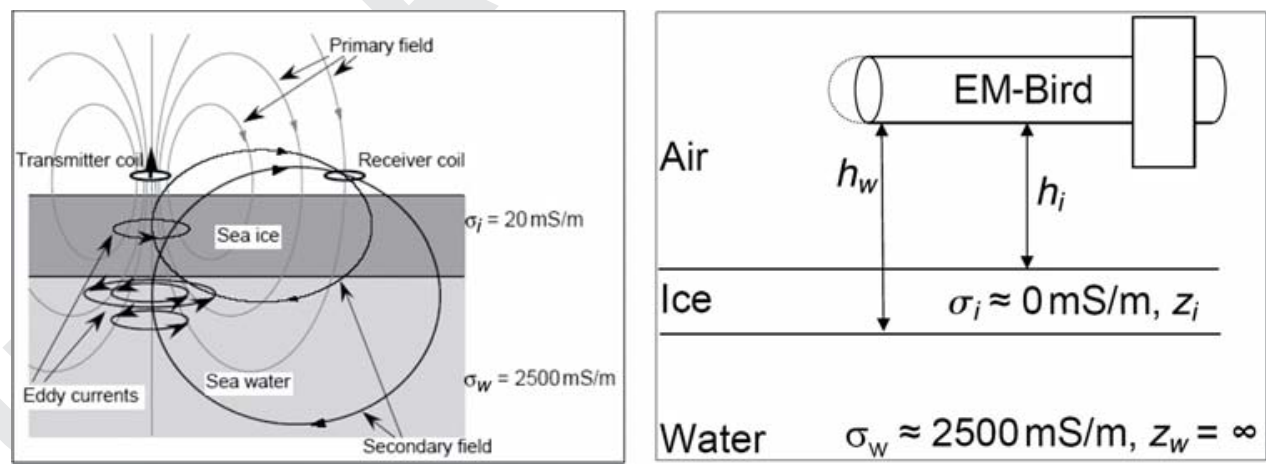

Fig. 4.9 Left: Principle of EM ice thickness sounding, showing the generation of a primary field by a transmitter coil and induction of a secondary field, whose strength and phase are measured by a receiver coil. Right: If an EM instrument is operated above the ice, ice thickness $Z_{i}$ is obtained from the difference of measurements of the instrument's height above the water and above the ice surface, $h_{w}$ and $h_{i}$, respectively (Haas et al., 2008b). $h_{i}$ is usually determined with a laser altimeter. Note that $Z_{i}$ corresponds to the total thickness, i.e. the sum of ice plus snow thickness. 
for the calculation of ice thickness $h$ from apparent conductivity $\sigma_{\text {a }}$ using a Geonics EM31 instrument (Haas et al., 1997). Similar equations have been derived by Haas \& Eicken (2001) and Eicken et al. (2001), with slightly varying coefficients due to different modal thicknesses in the respective study regions.

The Geonics-EM31 is most widely used for sea ice thickness measurements and has a coil spacing of $3.66 \mathrm{~m}$ with an operating frequency of $9.8 \mathrm{kHz}$. For instruments with other frequencies and coil spacings, different equations would have to be developed. The equations can also be derived by numerical EM forward modelling, computing the EM response to a layered half-space (Anderson, 1979). More involved equations can be calculated from twoor three-dimensional EM models, which can also represent pressure ridges (Liu \& Becker, 1990).

Figure 4.2 has already shown two examples of ground-based EM profiles. These were obtained by pulling an EM instrument installed on a sledge over the ice. Comparison with drill-hole measurements reveals a good agreement within $\pm 0.1 \mathrm{~m}$ over level ice. However, there is quite some disagreement over deformed ice. As the induced eddy currents possess a finite lateral extent, the resulting ice thickness estimate is some average over a certain area, called the 'footprint'. Estimates of the footprint diameter range between 3.7 and 10 times the distance between the EM instrument and the water surface, depending on the instrument configuration (Kovacs et al., 1995; Reid et al., 2006). Consequently, EM measurements underestimate the maximum thickness of deformed ice such as ridge keels, because the induced eddy currents are also affected by the occurrence of water within and adjacent to deformed ice structures. The maximum thickness of pressure ridges can be underestimated by as much as $50 \%$.

EM measurements are hardly affected by seasonally varying ice properties, because these do not affect ice conductivity very much (Haas et al., 1997). However, surface flooding or the occurrence of sea water-filled gap layers due to rafting or internal melting can lead to underestimates of ice thickness by EM sounding if they are not detected (Haas, 1998; Uto et al., 2006).

An advantage of the EM technique is that it can be applied also from above the ice without any ground contact. In this case, the EM measurement determines the distance $h_{w}$ between the EM sensor and the water surface or ice underside, respectively (Fig. 4.9). The height $h_{i}$ of the instrument above the ice surface can be measured with a laser or sonar range finder. Ice thickness is then obtained by subtracting $h_{i}$ from $h_{w}$. This principle is widely applied from ships and aircrafts. However, it is important to note that the ice thickness thus obtained is the total, i.e. snow plus ice thickness, as the laser or sonar range finders do not penetrate into the snow cover.

Ship-borne measurements, performed from onboard icebreakers while steaming through the ice, can yield regional ice thickness information. They have been carried out under a variety of conditions primarily in thinner ice, allowing straight cruise tracks (Haas, 1998; Haas et al., 1999b, Reid et al., 2003; Uto et al., 2006). In addition, when performed in front of a ship or from another structure like a lighthouse or bridge pillar, these measurements can provide instant ice thickness information required for ship performance or ice load studies (Haas et al., 1999b; Haas \& Jochmann, 2003). However, ship-based measurements are obviously limited by the ice itself since ships cannot penetrate the thickest ice. More importantly, most ships follow the route of least resistance, which is the one with the thinnest or absent ice. Therefore, representative information on regional ice thickness distributions can only be obtained on dedicated, scientific cruises. 
The ultimate goal of EM sounding is to perform systematic, large-scale surveys using aircraft. Airborne sensors have been deployed from helicopters or fixed-wing aircrafts (Kovacs et al., 1987; Kovacs \& Holladay, 1990; Prinsenberg \& Holladay, 1993; Multala et al., 1996). Currently, two different types of helicopter systems are in operation: a towed instrument called an 'EM-Bird' (Haas et al., 2008b), and a system where the shell is hard mounted at the nose of the helicopter, the so-called 'IcePic' (Prinsenberg et al., 2002; Peterson et al., 2008). Extensive comparisons with drill-hole measurements and theoretical considerations have shown that the accuracy of these measurements over level ice is better than $10 \mathrm{~cm}$ (Pfaffling et al., 2007), but it is still unclear how ridge cross sections compare with results from other methods (Haas \& Jochmann, 2003).

The EM-birds of the German Alfred Wegener Institute and of the University of Alberta in Canada operate at frequencies of 3.6 and $112 \mathrm{kHz}$, and have a maximum coil spacing of $2.7 \mathrm{~m}$ with an overall length of $3.4 \mathrm{~m}$ (Fig. 4.10). The bird is towed under a helicopter with a $20-\mathrm{m}$ cable and operated $15-20 \mathrm{~m}$ above the ice surface. Its size and small weight of only $100 \mathrm{~kg}$ allow shipping to remote Arctic sites, operation by any kind of helicopter and deployment from small helicopter decks of icebreakers.

As can be seen from equation 4.4, the EM response decreases exponentially with increasing instrument height. Therefore, airborne systems must fly low and have to have very good signal-to-noise ratios to be able to resolve even small signal changes. This is particularly challenging for systems as small as the EM-bird or IcePic.

Figure 4.11 shows two typical examples of ice thickness profiles obtained by helicopterborne EM sounding. The profiles are superimposed on Synthetic Aperture Radar (SAR) imagery acquired by the European Space Agency's (ESA) Envisat satellite, which give an overview of the general ice conditions at the time of the helicopter flights. The data over the Lincoln Sea was obtained on May 14, 2005 (Fig. 4.11, left) (Haas et al., 2006). A mixture of darker first-year ice and brighter multiyear ice is visible on the SAR image. Their different ice thicknesses are well represented by the EM data, which also shows an ice thickness of 0 $\mathrm{m}$ over a bright-appearing polynya at the mouth of Nares Strait. First-year ice thicknesses ranged between 1 and $2.5 \mathrm{~m}$, while the multiyear ice thickness mostly exceeded $4 \mathrm{~m}$. Similarly,

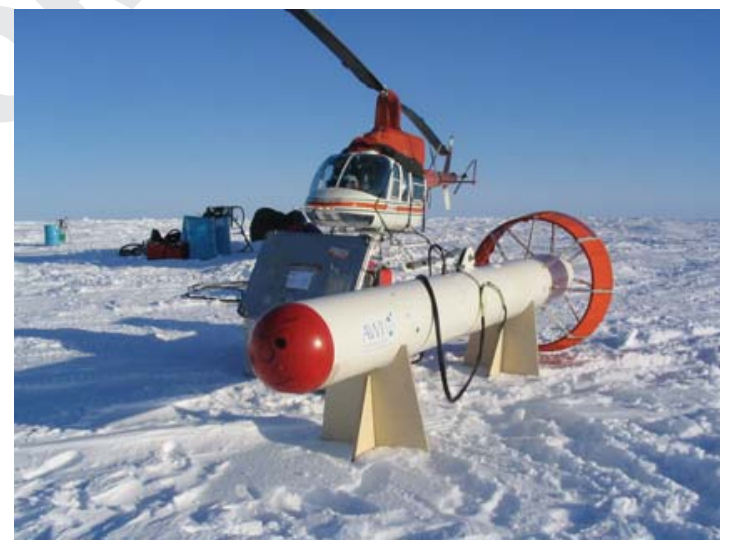

Fig. 4.10 The Alfred Wegener Institute's EM-bird with its towing helicopter in the background on an ice floe in the Arctic (photo by S. Goebell). 

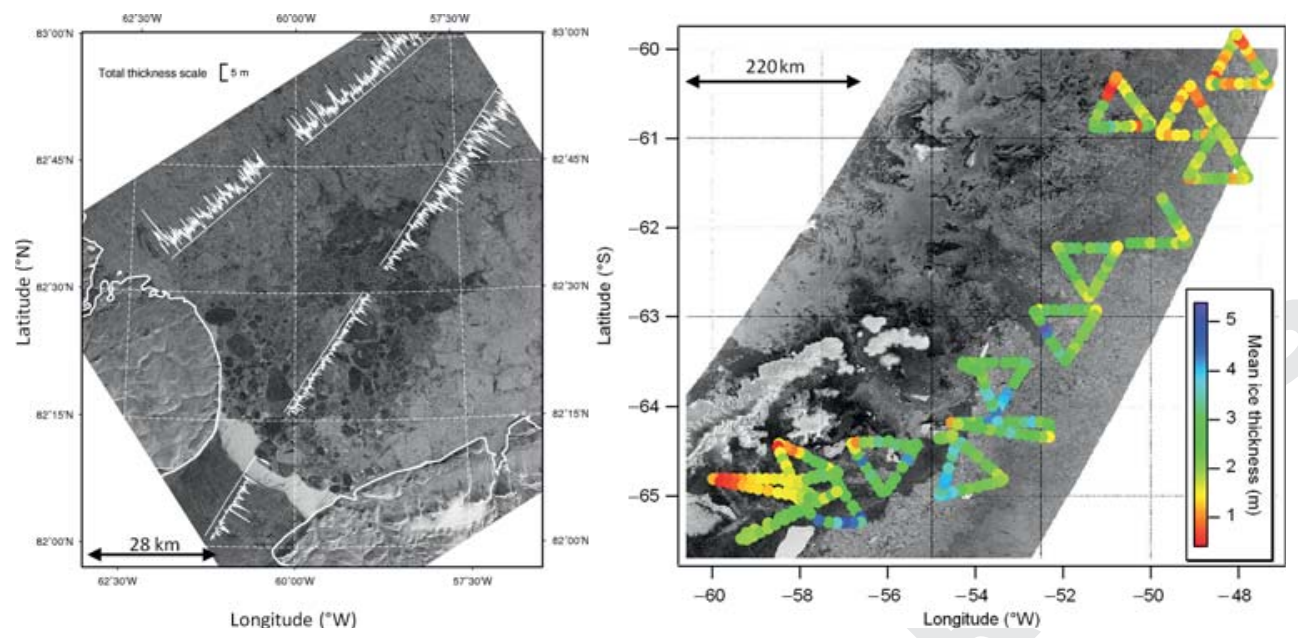

Fig. 4.11 Typical examples of thickness profiles obtained by helicopter-borne EM sounding, and comparison with satellite SAR images. Left: Ice thickness and ice conditions in the Lincoln Sea on 14 May 2005 (Haas et al., 2006) and (right) in the northwestern Weddell Sea between 19 September and 10 October 2006, with the SAR image showing ice conditions on 19 September. Coloured dots show mean ice thickness in 8-km long profile sections. Note the difference scales of maps

ice thicknesses and SAR backscatter delineate different ice regimes of heavily deformed firstand second-year ice and level, young first-year ice in the northwestern Weddell Sea between September 19 and October 10, 2006 (Fig. 4.11, right). The heavily deformed ice with high backscatter in the right part of the image had mean thicknesses of more than $3 \mathrm{~m}$ in the south, and was thinning northward, probably as a result of divergence and melting, which both affect the mean thickness. The first-year ice between the band of heavily deformed ice and the Antarctic Peninsula originated from a polynya in the Larsen A and B bays in the southwestern corner of the image. It had modal thicknesses of up to $1.5 \mathrm{~m}$, with mean thicknesses of $2 \mathrm{~m}$ and more. However, a strong gradient towards the refrozen polynya was observed, where mean ice thicknesses only amounted to around $0.5 \mathrm{~m}$.

As a by-product of ship-based and airborne EM measurements, the surface profile of the ice is obtained from the laser data. This provides information on surface roughness and the calculation of pressure ridge statistics (von Saldern et al., 2006; Peterson et al., 2008). The laser measurements could thus partially compensate for the lack of accuracy of EM data over pressure ridges, if relationships between the height of ridges and their overall thickness could be established. At the very least, ice regimes can be described by their EM-derived distinct level ice thickness and the laser-estimated amount of ridged ice.

The laser altimeter surveys of EM systems, or independent laser altimeter measurements, can be combined with differential GPS to accurately determine the altitude of the laser system over a reference surface like the water surface. Then, the freeboard of the ice can be estimated, and can be used as a measure of ice thickness (Hvidegaard \& Forsberg, 2002). The estimation of ice thickness from airborne or satellite altimetric measurements of freeboard will be discussed in the next section. 


\section{Satellite altimetry}

Significant progress has been made in recent years with the application of satellite laser and radar altimetry for the retrieval of ice freeboard or snow surface elevation, and for the estimation of ice thickness from those (Laxon et al., 2003; Kwok et al., 2004; Giles et al., 2008; Kwok \& Cunningham, 2008; Zwally et al., 2008). Figures 4.6 and 4.7 have already given examples of surface elevation and ice thickness maps of the Arctic and Southern oceans thus obtained. Figure 4.12 compares ICESat surface elevation and reflectivity with ice conditions revealed on a SAR image. With satellite altimeters, the distance between the satellite and the surface of the earth is measured. Relative surface height differences between the ice and water are observed to estimate sea ice freeboard or surface elevation. The calculation of ice thickness from these measurements relies on several assumptions about snow thickness and density, as well as the densities of ice and snow.

Two different kinds of altimeters are employed. The ESA's ERS and Envisat satellites carry Ku-band (e.g. $13.8 \mathrm{GHz}$ ) radar altimeters, while NASA's ICESat operates a laser altimeter. These are generally different in their penetration characteristics for snow and sea ice, and in their spatial resolution. Penetration characteristics are particularly important for sea ice measurements. While the near-infrared wavelengths of lasers do not penetrate into snow and ice and are scattered at the upper snow surface, radar altimeter wavelengths penetrate the snow to some degree, and the reflections are generally believed to originate from the snow/ ice-interface (Laxon et al., 2003). Therefore, with laser altimeters, the elevation of the snow surface $Z_{s e}$ is obtained, while with radar altimeters the freeboard $Z_{f b}$ of the ice is retrieved. Accordingly, different equations for the calculation of ice thickness $Z_{i}$ are applied, which result from Archimedes Law and the general isostasy of the ice:

$$
\text { For laser altimetry: } z_{i}=\left(\frac{\rho_{w}}{\rho_{w}-\rho_{i}}\right) z_{s e}-\left(\frac{\rho_{w}-\rho_{s}}{\rho_{w}-\rho_{i}}\right) z_{s}
$$

(Equation 4.5a)

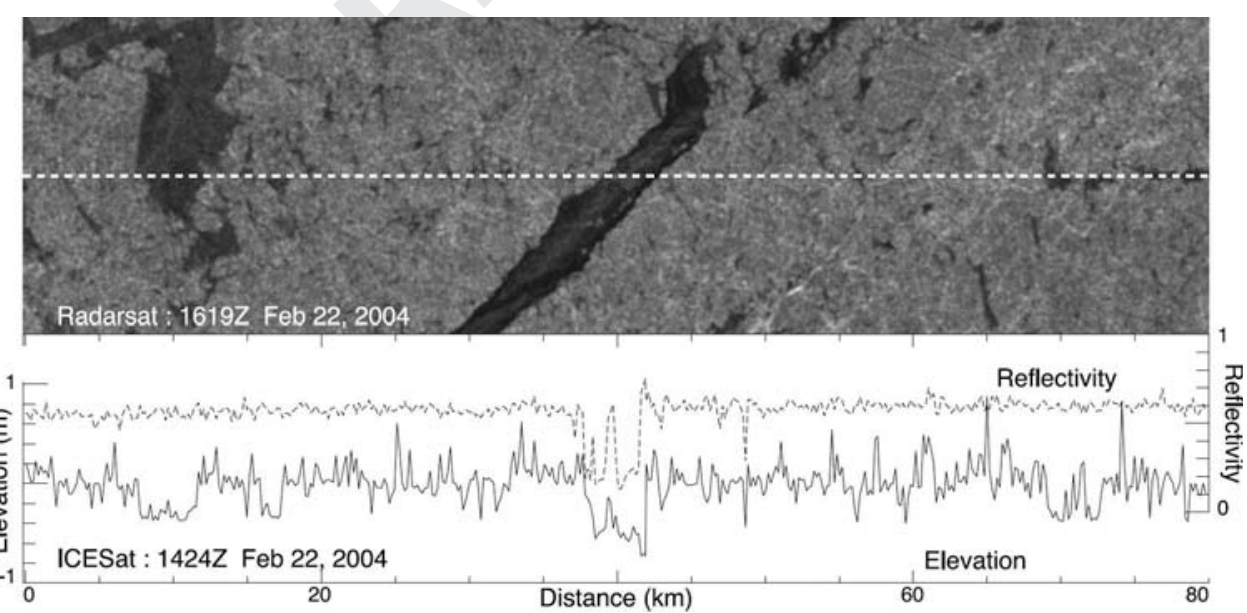

Fig. 4.12 Example of 80-km long ICESat profile from the Arctic Ocean and comparison with near-coincident Radarsat SAR image (Kwok et al., 2006). The ICESat track is shown on the SAR image as white dashed line. Lower panel shows the elevation (solid, centred around mean) and reflectivity profiles (dashed). 
For radar altimetry: $z_{i}=\left(\frac{\rho_{w}}{\rho_{w}-\rho_{i}}\right) z_{f b}-\left(\frac{\rho_{s}}{\rho_{w}-\rho_{i}}\right) z_{s} \quad$ (Equation 4.5b)

with the densities $\rho_{w}, \rho_{i}$, and $\rho_{s}$ of water, ice and snow, respectively, and snow thickness $Z_{s}$.

With typical densities of $\rho_{w}=1024 \mathrm{~kg} \mathrm{~m}^{-3}, \rho_{i}=925 \mathrm{~kg} \mathrm{~m}^{-3}$ and $\rho_{s}=300 \mathrm{~kg} \mathrm{~m}^{-3}$, the first term in these equations implies an approximately tenfold amplification of freeboard uncertainties for the calculation of ice thickness for both methods. However, it is also important to note that the second terms are different, resulting in a stark difference in the sensitivity of thickness retrievals to uncertainties in snow thickness. The term is approximately 7 for laser altimetry and approximately 3 for radar altimetry. Therefore, snow thickness uncertainties in laser altimeter data contribute to more than twice as large uncertainties in retrieved ice thicknesses than in radar altimeter data.

A comprehensive analysis of the sensitivity of ice thickness calculations according to equation 4.5 to uncertainties in snow and ice properties has been performed by Kwok \& Cunningham (2008). Results show that the overall uncertainty of thickness retrievals from altimetry can be reduced to less than 0.7 to $0.5 \mathrm{~m}$.

However, another challenge of altimeter measurements of ice freeboard and surface elevation is the retrieval of the local water level, which is required as a reference. Small-scale sea surface height variations occur due to tides and currents, unknown geoid undulations, and temporal variations due to weather-related surface pressure changes. Therefore, measurements rely on the occurrence of open water regions within the pack ice which can be used as tie-points for the reconstruction of the water level. Echo shape and amplitude information of the laser and radar signals are used to support the detection of tie-points (Kwok et al., 2006). Figure 4.12 shows that low elevations often coincide with low reflectivity, indicative of open water or a refreezing lead. The presence of the lead is confirmed by the SAR image. However, note that only the central lead is clearly identifiable in the reflectivity data. Larger errors can be introduced in the freeboard retrievals if tie-points cannot be clearly and frequently detected.

Altimetric measurements are essentially one-dimensional along the satellite track. ICESat performs a measurement every $170 \mathrm{~m}$ with a footprint diameter of $70 \mathrm{~m}$. The ERS radar altimeter obtained a measurement every $330 \mathrm{~m}$, but with a footprint of several kilometres due to the nature of the pulse-limited radar altimeter signals. Therefore, large regions of the earth surface including the poles are not covered by satellite altimeters at all. There are tradeoffs between orbit inclination, repeat orbit intervals and ground coverage. For example, higher across-track coverage can be achieved with longer repeat intervals, but then temporal changes cannot be so well resolved. A typical orbit repeat period is 30 days. More frequent measurements are only performed at crossover locations of descending and ascending orbits. In addition, the uncertainty of individual point measurements can be large, and sufficient accuracy is only obtained with significant spatial and temporal averaging.

Validation of altimetric ice thickness measurements is difficult due to the footprint of the methods and the variable ice conditions in-between. It is still not clear if the retrieved freeboard values actually represent the mean freeboard, modal freeboard or maximum freeboard within the footprint. Although radar signals might penetrate through fresh, cold snow unaffectedly, there are indications that this assumption is not valid for older and metamorphic snow. 
Some of the problems of conventional radar altimetry related to the footprint size and orbit configuration will be overcome by ESA's CryoSat mission to be launched in late 2009. In contrast to previous altimeter missions, which were designed to map the world's oceans, CryoSat is dedicated to observations of sea ice and ice sheet thickness, and will therefore operate with a high inclination of $92^{\circ}$, allowing observations to as far as $88^{\circ}$ North and South. Its only payload is a Synthetic-Aperture Interferometric Radar Altimeter (SIRAL) (Wingham et al., 2004). With synthetic-aperture processing, multiple, coherent measurements of the same surface location are taken at by different beams at different viewing angles while the satellite passes over that location. These measurements can later be reconstructed and stacked, thereby increasing the along-track resolution and decreasing the along-track footprint to approximately $250 \mathrm{~m}$. With this reduced footprint size, it will be much better possible to distinguish between measurements over ice and water, thereby improving the identification of tie-points and reconstruction of the water level for better freeboard measurements.

\section{Other satellite methods}

Except altimeters, most other satellite sensors are imaging instruments, which provide areal information about specific surface properties rather than any information from inside the ice or its underside. However, these surface properties can be used to identify the type and age of the ice, which can serve as a proxy for ice thickness.

Thin ice has a warmer surface than thick ice as long as it is not yet snow covered, and its surface temperature decreases with increasing thickness. Therefore, it is well separable from thicker ice by means of thermal infrared techniques. Yu \& Rothrock (1996) have suggested an algorithm based on thermal channels of the Advanced Very High Resolution Radiometer (AVHRR) sensor to obtain the thickness of snow-free ice up to $0.5 \mathrm{~m}$ thick with a spatial resolution of $1.1 \mathrm{~km}$. These observations are particularly valuable over the thin ice regions of polynyas. The method has been refined and adapted to data of the Moderate Resolution Imaging Spectroradiometer (MODIS) instrument with higher spatial resolution of $250 \mathrm{~m}$ by Kwok et al. (2007), as shown in Fig. 4.13. Note that the surface air temperature has to be known for the application of these algorithms, which are taken from numerical reanalysis data or weather stations. Applicability of these algorithms is also limited to cloud-free situations.

Similarly, microwave brightness temperatures as observed by passive microwave sensors are affected by surface temperature. Measurements of different channels of the Special Sensor Microwave/Imager (SSM/I) and Advanced Microwave Scanning Radiometer (AMSR) have been combined to derive thin ice thicknesses up to $0.2 \mathrm{~m}$ over various polynyas in the Arctic and Antarctic (Martin et al., 2004; Kwok et al., 2007). These measurements are not affected by clouds, but have a lower spatial resolution of between 12 and $25 \mathrm{~km}$.

Microwave emissivity, absorption and scattering are also sensitive to varying properties of the surface of thicker ice. These are mainly dependent on the ice and snow salinity and small-scale surface roughness. As shown in Chapter 2, large changes of surface salinity occur in first-year ice once it experiences its first melting season. The salt drains into deeper layers or is flushed by melt water. The pores widen considerably and brine is replaced by air. Therefore, second- and multiyear ice are characterized by lower microwave emissivities and higher radar backscatter coefficients than first-year ice. Consequently, mapping of regions with low brightness temperatures or high radar backscatter can provide estimates on the 


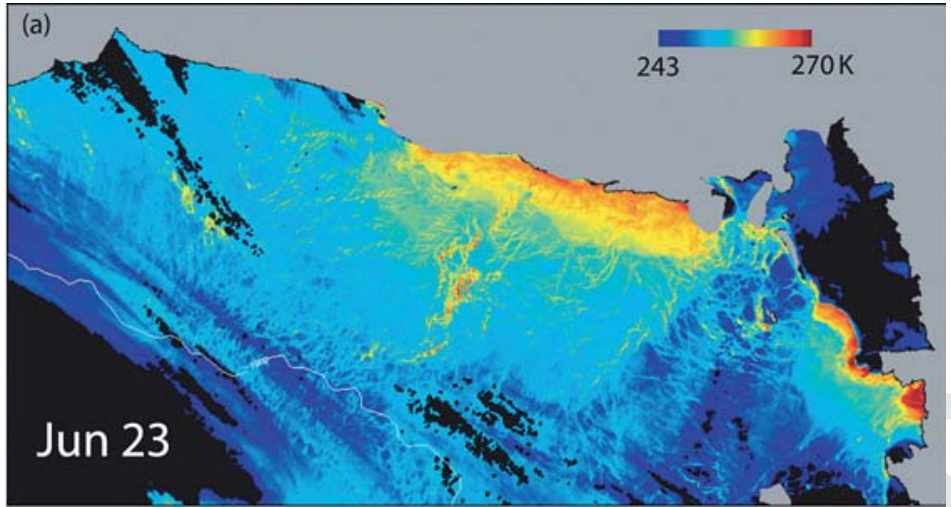

(b)

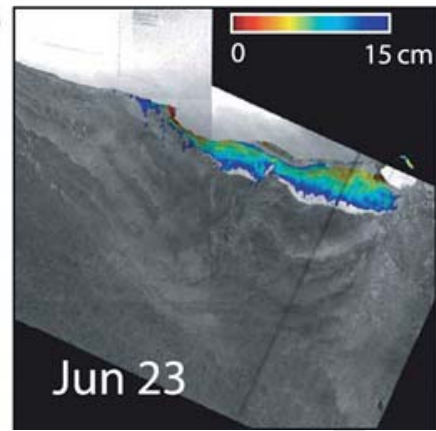

(c)

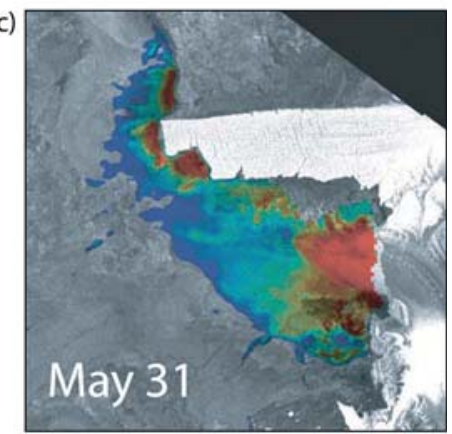

Fig. 4.13 Three examples of ice surface temperature fields and thin ice thickness $(0-15 \mathrm{~cm})$ derived from MODIS data in the Ross Sea, Antarctica (Kwok et al., 2007). (a) Ice surface temperature of the Ross Sea region (23 June). Note that part of the image is covered by cloud obscuring the view to the ice surface, indicated by black colour. (b,c) MODISderived ice thickness at the Ross Sea (23 June) and Terra Nova Bay (31 May), and polynyas overlaid on near-coincident SAR images. The MODIS IST is at 1-km resolution; the SAR data resolution is degraded to match that of MODIS

relative amount of thick multiyear and thin first-year ice. Using low-resolution, Ku-band backscatter data from the QuikScat satellite, Kwok (2004, 2007) and Nghiem et al. (2007) have demonstrated the decreasing amount of multiyear ice in the Arctic as one component of the present rapid change (see below). However, quantitative thickness information or thickness distributions cannot be obtained from these data.

SAR imagery of the ESA's ERS-1\&2 and Envisat satellites, as well as of the Canadian RADARSAT-1\&2 satellites, provides the same qualitative differentiation between thin and thick ice, and can well distinguish between regions of first- and multiyear ice. This was already demonstrated with the examples in Figs 4.11, 4.12 and 4.13 above. The high horizontal resolution of $12-75 \mathrm{~m}$ is sufficient to resolve leads and to partially identify ridges or ridge zones. These features have different backscattering properties than the surrounding ice. Leads are covered by open water or thin new ice, which is rapidly thickening. They may also be recognizable by their linear extended shape, and the saline ice is easily distinguished by its lower backscatter compared with the surrounding older ice. However, frost flowers, rafting or multiple scattering over very thin ice can also cause high backscatter of leads. Kwok et al. (1999) have developed the so-called Radarsat Geophysical Processor System (RGPS) which 
tracks leads in successive SAR images and computes their thickness distribution by means of a thermodynamic model. RGPS also computes the thickening of the new ice by deformation if leads close under convergent drift conditions. The overall thickness distribution, including thick floes, is difficult to obtain though.

The number of ridges and the degree of deformation are relative measures of ice thickness. Ridge sails consist of piled ice blocks with arbitrarily tilted sidewalls. These provide a number of interfaces pointing normally to the incident radar signal. Thus, backscatter is higher than from the surrounding level ice. In addition, ridge backscatter can also rise by increased volume scattering, as aged ridge blocks become more weathered and porous. Therefore, single large ridges can be seen in SAR images. However, smaller ridges also contribute to the mean backscatter of a certain image pixel. There are indications that the backscatter distribution of a certain region includes information on the amount of ridges in this region (Haas et al., 1999a; Karvonen et al., 2004).

\subsection{Ice thickness variability}

\section{Decadal thickness variability in the Arctic}

As outlined above, the thickness distributions shown in Fig. 4.5 represent 9-year average fields. Although average conditions over even longer-time periods look similar (Bourke \& Garret, 1987), on timescales of years and decades, the thickness distribution shows large interannual and decadal variability, and longer-term trends. Most spectacular observations of changes of the Arctic ice cover have been published by Rothrock et al. (1999). They compared submarine sonar data obtained in 28 regions of the Arctic Ocean during the period 1958-76 with those gathered in the same regions between 1993 and 1997. In all regions, a decrease in the mean draft was observed (Fig. 4.14). On average, there was a $1.3 \mathrm{~m}$ decrease from a mean draft of $3.1 \mathrm{~m}$ in the earlier period to a mean draft of $1.8 \mathrm{~m}$ in the $1990 \mathrm{~s}$, equivalent to a reduction of $42 \%$ of ice thickness. The thinning was most pronounced in the Siberian Arctic and Nansen Basin, where the average decrease of draft was $1.8 \mathrm{~m}$. Although their results indicated a continued thinning in some regions during the 1990s, the study essentially only compared two distinct periods (1958-76 and 1993-97) with each other. Therefore, it is unclear if the results are an indication of a trend or just represent two arbitrary samples of a varying parameter.

Figure 4.15 shows the mean annual ice volume in the Arctic from 1948 to 1999 as simulated with a dynamic-thermodynamic ice-ocean model (Rothrock \& Zhang, 2005). The figure clearly shows that there are large decadal ice volume fluctuations of as much as $5 \times 10^{3} \mathrm{~km}^{3}$ around a mean volume of $22.5 \times 10^{3} \mathrm{~km}^{3}$. The data in fact show a marked thinning of about $37 \%$ between the 1960 s and the 1990 s, i.e. the period covered by Rothrock et al. (1999). However, for the complete model period, only a small decrease of ice volume of $-4 \%$ per decade was obtained. The model results indicate that this decrease is unevenly distributed over different regions of the Arctic. The largest decrease was obtained from the East Siberian Sea and central Arctic, whereas the regions north off the Canadian Archipelago showed slightly increasing ice thicknesses.

The causes for the modeled variability and trends are further examined in Fig. 4.15b, which shows a separation between the impacts of changes in wind forcing and temperature forcing. $V_{W}$ represents ice volume changes due purely to variations in wind forcing, and $V_{T}$ 


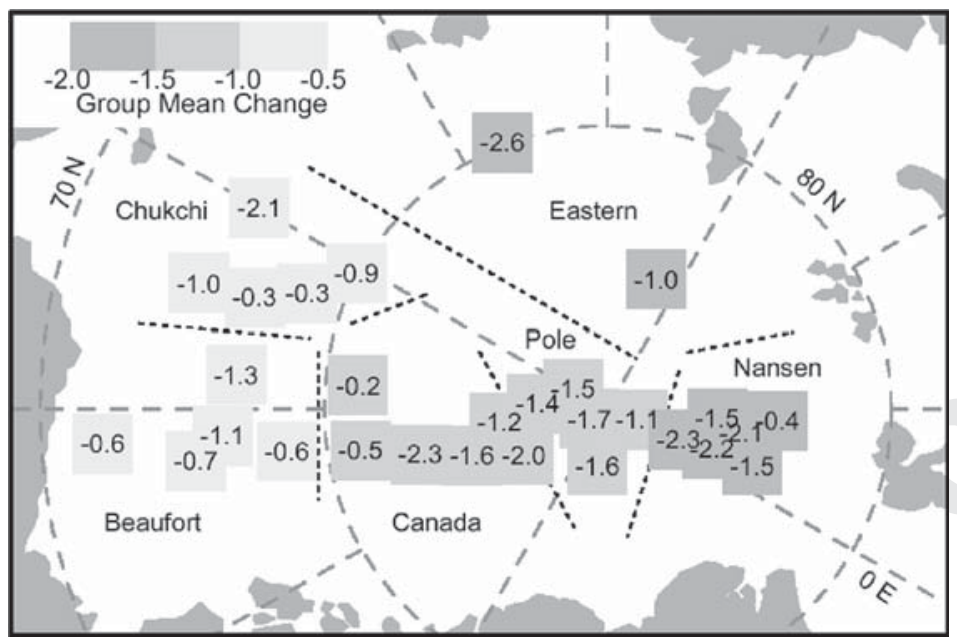

Fig. 4.14 Map of the Arctic showing the regions of coincident submarine tracks in 1958-76 and 1993-97. Numbers indicate the ice thickness difference between the two periods. From Rothrock et al. (1999)

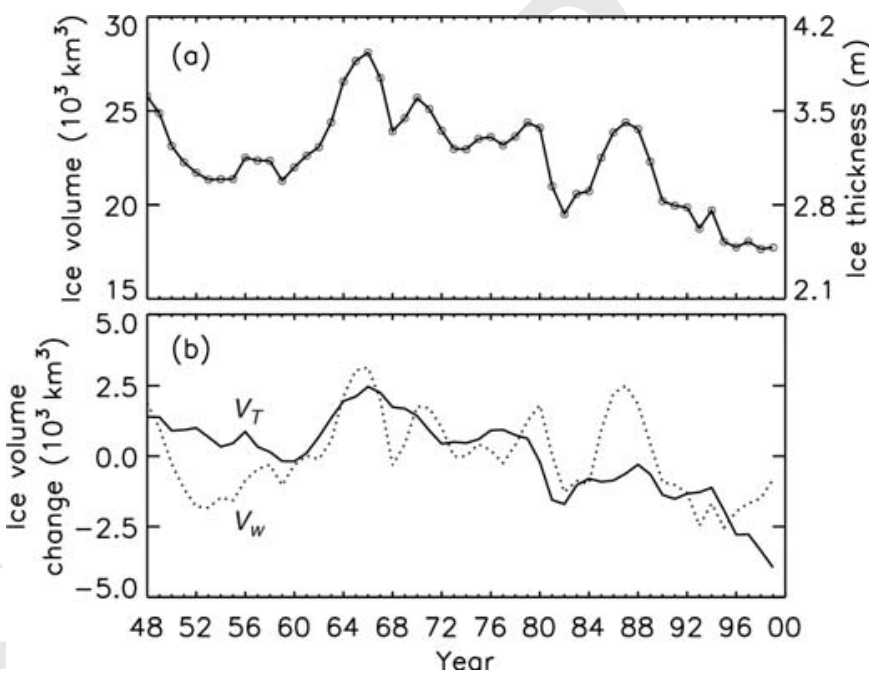

Fig. 4.15 (a) Modelled ice volume within the Arctic Ocean 1948-99 (Rothrock \& Zhang, 2005). The 52-year mean annual ice-covered area of $6.91 \times 106 \mathrm{~km}^{2}$ is used to convert volume to an approximate thickness scale on the right axis. (b) Wind-forced volume change $V_{w}(t)$ (dotted line) and the temperature-forced component $V_{T}(t)$ (solid line), as defined in the text.

due to variations of only thermal forcing. VW was calculated by retaining the interannually varying winds, but by using only the long-term average annual cycle of air temperatures. $V T$ was similarly obtained by using variable temperatures and constant, average winds. Figure $4.15 \mathrm{~b}$ shows that $V W$ contributes approximately two-thirds of the total ice volume variability. It does not possess any clear trend. However, VT shows less variability but a clear trend. In conclusion, these results suggest that the changes observed over the past couple 
of decades are the result of strong interannual variability mainly due to variable winds, which are superimposed on a longer-term trend of decreasing ice volume due to warming temperatures.

Tucker et al. (2001) compared complementary submarine draft measurements performed between off Alaska and the North Pole between 1985 and 1988 with data from the same transects obtained in 1992-94. During this short period, mean ice drafts decreased by $1.5 \mathrm{~m}$. Again, it remains unclear if this represents just some variability or an actual trend. The data are in agreement with the ice volume time series presented in Fig. 4.15. However, Tucker et al. (2001) took a step further in relating their results to changes in the ice drift regime. While the Beaufort Gyre was well developed in the 1980s, it weakened considerably in the 1990s. This led to stronger ice-divergence and to less production of thick, deformed ice. The different circulation regimes also resulted in shorter residence times of the ice in the Canadian Basin, and therefore less time to accumulate deformed ice.

The relationships between ice thickness changes and different circulation regimes observed by Tucker et al. (2001) are thoroughly demonstrated by a coupled dynamic-thermodynamic ice-ocean model of Zhang et al. (2000) for the period 1979-96. This period was characterized by two distinct circulation regimes during 1979-88 and 1989-96, respectively. These different circulation regimes are characterized by high and low North Atlantic Oscillation $(\mathrm{NAO})$ and Arctic Oscillation $(\mathrm{AO})$ indices, parameters derived from the difference and variability of sea level pressure in the Arctic and at lower latitudes (Hurrel, 1995; Thompson \& Wallace, 1998). The period $1979-88$ was characterized by low NAO and AO indices, and therefore high sea level pressure over the central Arctic, while the period 1989-96 was characterized by high NAO and AO indices and low sea level pressure. Figure 4.16a,b shows the mean sea level pressure contours and modelled ice velocity fields for both periods. Figure $4.16 \mathrm{c}, \mathrm{d}$ shows the anomalies of ice velocity fields based on the differences between the 1979-88 and 1989-96 fields and the mean field of 1979-96, respectively. The latter period (1989-96) was characterized by smaller pressure gradients and a weaker Beaufort Gyre, which had also retreated more towards the Canadian Coast. Essentially, the anomaly fields show reversed conditions, with an anticyclonic circulation anomaly in 1979-88 and a cyclonic anomaly in 1989-96. Figure 4.17 shows the corresponding thickness anomalies, derived from the difference of the thickness fields in 1979-88 and in 1989-96. There was strong thinning in the East Siberian Sea (up to $-2.5 \mathrm{~m}$ ) and the central Arctic, whereas ice thickness increased in the Beaufort Sea and off the Canadian and Alaskan coasts. Ice volume decreased by $28 \%$ in the eastern Arctic and simultaneously increased by $16 \%$ in the western Arctic. Overall, in the whole Arctic it decreased by only 6\% between 1979-88 and 1989-96. Note that the thickness measurements reported by Rothrock et al. (1999) and Tucker et al. (2001) were mostly in the regions of modelled thickness decrease and were consistent with these model results.

The results of Zhang et al. (2000) show that the ice thickness changes between 1979 and 1996 can almost exclusively be attributed to changes in the circulation regimes. This mainly led to different amounts of ice exported from the western into the eastern Arctic. The study therefore shows that on shorter timescales dynamics are far more important than thermodynamics in shaping the overall thickness distribution in the Arctic, in agreement with the results shown in Fig. 4.15. Similar results were found by Holloway and Sou (2002).

However, Zhang et al. (2000) also clearly demonstrate that thermodynamics play an important role in modifying the dynamically caused differences, both through negative and 


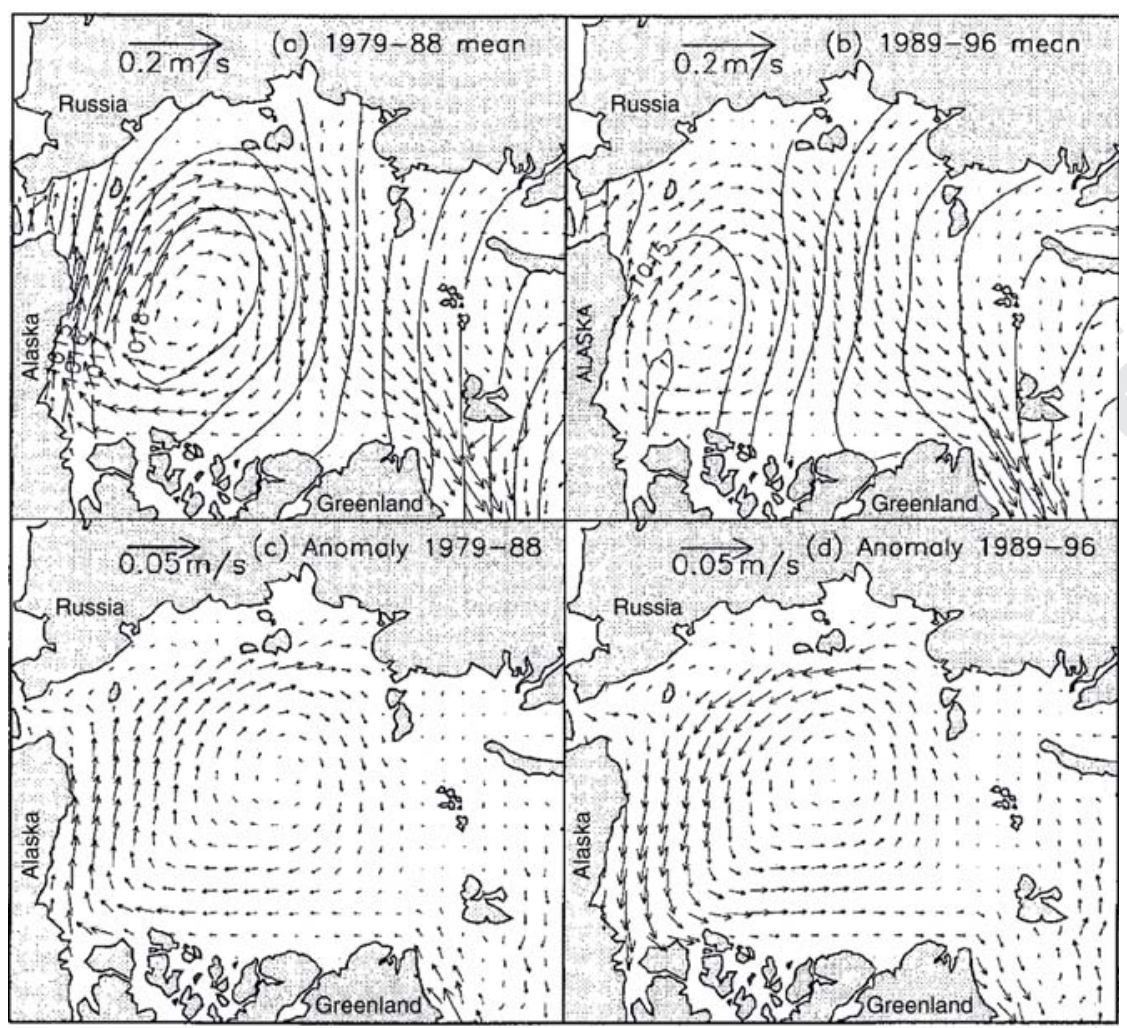

Fig. 4.16 Simulated mean ice velocity fields and annual mean sea level pressure contours for (a) 1979-88 and (b) 1989-96 (Zhang et al., 2000). Anomaly fields of ice velocity based on the differences (c) between the 1979-88 mean and the 1979-96 mean and (d) between the 1989-96 mean and the 1979-96 mean.

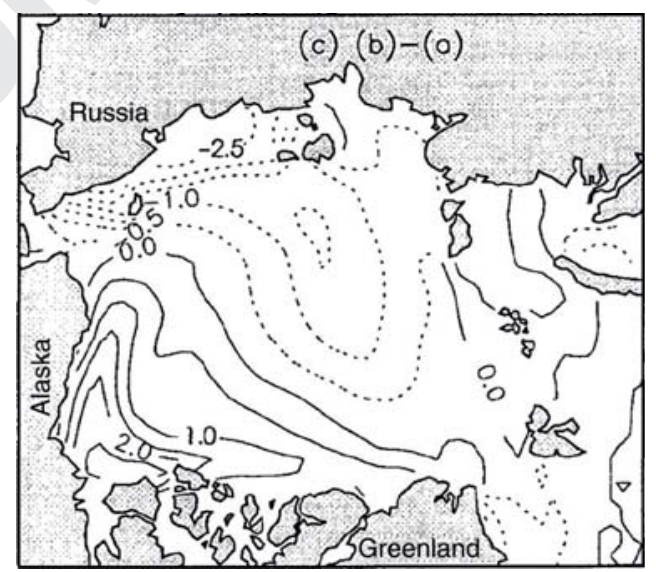

Fig. 4.17 Difference between the simulated ice thickness fields for 1979-88 and 1989-96. From Zhang et al. (2000) 
positive feedback mechanisms. The different circulation regimes also caused differences in the ice concentration fields. Between 1979-88 and 1989-96, there was a decrease of mean ice concentration in the eastern Arctic and an increase in the western Arctic, which were most pronounced during summer. The positive feedback was the higher absorption of incident solar radiation in the mixed layer due to an overall decrease of surface albedo caused by larger areas of open water. This led to enhanced lateral and bottom melting and to a later onset of freezing, consequently enhancing the thinning. However, due to the thinner ice and more open water, freezing rates during winter were also higher, and therefore ice growth increased. The net ice production remained almost constant under the different circulation regimes.

Cyclonic and anticyclonic circulation regimes were shown to follow each other with periods of 7-15 years (Proshutinsky \& Johnson, 1997). Therefore, it is quite likely that these also cause simultaneous long-term ice volume changes such as those shown in Fig. 4.15. This high level of dynamically caused variability makes the detection of temperature-induced climate changes very complicated.

\section{Present day, interannual thickness variability}

Superimposed on the decadal thickness variations are large seasonal and interannual thickness variations. Only a few studies have had the opportunity to make repeated surveys in the same region over a couple of years. Among those are moored ULS measurements, e.g. in the Weddell Sea (Strass \& Fahrbach, 1998; Harms et al., 2001), the Beaufort Sea (Melling \& Riedel, 1995, 2004) and the Fram Strait (Vinje et al., 1998). The latter study showed that the ice volume flux through Fram Strait is well explained by changes of the NAO, and thus possesses a pronounced interannual variability.

On the contrary, results of satellite radar altimetry measurements by Laxon et al. (2003) showed the importance of changes of thermodynamic boundary conditions for the interannual thickness variability. They observed anomalies of mean winter ice thickness over the whole Arctic Basin between 1993 and 2001, which compared well with observations of the melt season length in the respective previous summer obtained from passive microwave satellite measurements. Thickness change from one year to the other correlated well with the length of the melt season in-between. A possible explanation of this observation might be that changes in circulation which would redistribute ice from one region of the Arctic Ocean to another are averaged out if observations over the whole Arctic are considered, and therefore thermodynamic changes would be more dominant.

However, large ice thickness changes were observed by means of EM sounding in the Laptev Sea in the summers of 1993, 1995 and 1996, and demonstrated the close interrelation between dynamic and thermodynamic processes (Haas \& Eicken, 2001). With mean and modal thicknesses of 1.8 and $1.25 \mathrm{~m}$, ice thickness was minimal in 1995. It was maximal in 1996, when the mean and modal thickness amounted to 2.0 and $1.85 \mathrm{~m}$. Mean and modal thicknesses were intermediate in 1993, with values of 1.85 and $1.75 \mathrm{~m}$, respectively. There was strong, intermediate and no melt pond coverage in 1995, 1993 and 1996, respectively. Satellite data showed that the ice coverage of the Laptev Sea assumed a record minimum in 1995, and a record maximum in 1996, since satellite observations began in 1978 .

The interannual differences could be well explained by the prevailing mean atmospheric circulation during July and August in each of the three summers, which was 'normal' in 
1993, but was characterized by high pressure over the central Arctic in 1995, and a deep low centred over the North Pole in 1996. The situation in 1995 favoured the northward advection of the ice edge, and the inflow of warm air from the south, which caused strong surface melt. In contrast, the low pressure over the North Pole in 1996 resulted in strong cyclonic geostrophic air and ice circulation. This moved the ice into the marginal seas, causing high ice coverage, and prevented the advection of warm air from the South, preventing surface melting. The result showed the importance of the strength and location of the summer cyclonic atmospheric circulation pattern for the advection of ice and occurrence of surface melt. It is also remarkable that ice thicknesses in 1996 were maximal despite a late onset of autumn freeze-up in 1995, which occurred 3 weeks later than on average due to the storage of heat in the water. However, it is not clear whether the thick ice in 1996 was due to stronger than normal ice growth or just due to the absence of summer melt. This is a problem of interpreting end-of-summer ice thicknesses, since it remains unclear if reduced (increased) thicknesses are due to reduced (increased) winter growth or increased (decreased) summer melt.

The extreme situation of 1995 and 1996 might provide an example of how a year with maximum ice coverage can be reached even after a minimum year. As much as special atmospheric conditions have favoured the rapid summer ice decline between 2006 and 2007 (Stroeve et al., 2008), a similar situation as in 1996 could still contribute to an at least partial recovery of Arctic ice conditions in the coming years.

Another presently observed consequence of circulation changes in the Arctic Ocean is the reduction of the amount of perennial and old ice (Kwok, 2007; Maslanik et al., 2007; Nghiem et al., 2007). These observations are based on satellite backscatter and emissivity measurements in more recent times, and on the tracking of buoys deployed by the International Arctic Buoy Program since the 1970s and utilization of numerical weather reanalysis data (Rigor \& Wallace, 2004). The changes of ice age are an indication of overall reduced ice volume. However, they also complicate the interpretation of observations of actual thickness changes. Figure 4.18 shows maps of the locations of ground-based and airborne EM thickness profiles obtained during summer in the region of the North Pole during six sporadic measurement campaigns between 1991 and 2007 (Haas et al., 2008a). The resulting thickness distributions are shown in the right part of the figure. It can be seen that modal thicknesses decreased from $2.5 \mathrm{~m}$ in 1991 to $1.9 \mathrm{~m}$ in 2001 and $2.2 \mathrm{~m}$ in 2004. In the summer of 2007 , modal thickness was only 0.9 m, i.e. $53 \%$ less than in 2001 . Mean thicknesses decreased at similar rates (Haas et al., 2008a). The decreasing modal thicknesses indicate a general increase of heat fluxes towards the ice. However, the maps in Fig. 4.18 also show that the large thinning observed in 2007 was accompanied by a replacement of older ice by first-year ice. In fact, in the summer of 2007, the region of the North Pole was only covered by first-year ice for the first time since ice age information is available. In April 2007, the region was still covered by second-year ice. However, Fig. 4.18 shows that also the second-year ice modal thickness was only $1.65 \mathrm{~m}$ after seasonal adjustment, i.e. 20\% less than in the summer of 2001.

These results demonstrate that the replacement of older ice by first-year ice is accompanied by abrupt thinning, which is superimposed on general trends of thermodynamically induced thinning trends. In the summer of 2007, the first-year ice in the region of the North Pole was so thin that only slightly more thinning in coming years could soon result in an ice-free North Pole during summer. 

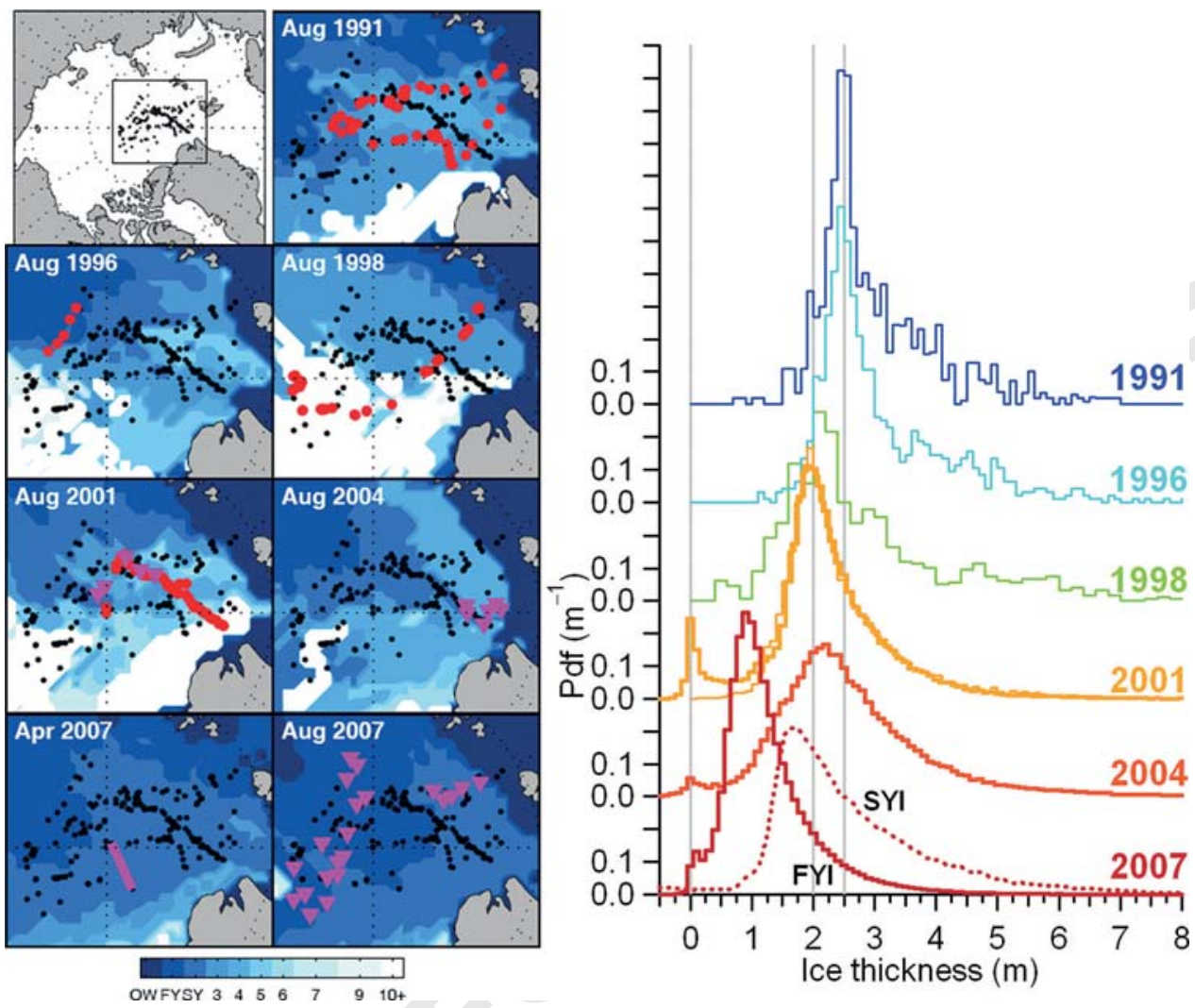

Fig. 4.18 Late summer ice age (left) and thickness (right) in the region of the North Pole between 1991 and 2007 (Haas et al., 2008a). Thicknesses were obtained by means of ground-based (thin lines, red circles) and HEM sounding (thick lines, magenta triangles). The second-year ice (SYI) distribution obtained in April 2007 was seasonally adjusted by $0.7 \mathrm{~m}$ to represent summer conditions. From Haas et al. (2008a).

\section{Seasonal thickness variability}

Apart from decadal and interannual variations, ice thickness is also subject to a strong seasonal cycle, which is superimposed on the lower-period changes, and which often exceeds longer-term changes in amplitude. The seasonal cycle results from prevailing thickening during the winter and from thinning during the summer, both through bottom and surface melt. The latter is most prominent in the Arctic, and results in the formation of melt ponds. Therefore, knowledge of the seasonal cycle, and of interannual variations of it, are important for the interpretation of thickness changes in general.

For example, an ice thickness change from one summer to the next can be the result of reduced freezing in the preceding winter, or of increased melting in the actual summer when the measurements have been performed, or both. If measurements are performed in different seasons, they will have to be compensated for the seasonal cycle before they are comparable. For example, Rothrock et al.'s (1999) submarine measurements have been performed both in late spring and early summer, and in late summer/early fall. All these measurements (Fig. 4.14) were seasonally adjusted to September 15 by means of a seasonal cycle computed 
with an ice-ocean model of the Arctic Ocean. That model indicated a mean seasonal thickness cycle of $1.5 \mathrm{~m}$ between April and September 15, the seasonal minimum. Obviously, questions arise whether it is appropriate to use a model of the whole Arctic Ocean for the correction of observations which were mainly performed in the central Arctic Ocean, and if the amplitude of seasonal changes is uniform over large regions.

In a more recent study, Rothrock et al. (2008) separated the seasonal cycle from the submarine data themselves by means of multiple regression. The annual cycle of mean ice thickness in the central Arctic Ocean has a maximum on 30 April and a minimum on 30 October with a peak-to-trough amplitude of $1.12 \mathrm{~m}$, i.e. less than computed with the model in their earlier study.

Again, this mean cycle comprises both dynamic and thermodynamic components. As discussed above and shown by Perovich et al. (2003), the thermodynamic component of the seasonal cycle can be as high as obtained by Rothrock et al. (2008) for the mean, and varies strongly between different ice types and geographical regions. Typical, maximum winter growth rates can be estimated from first-year ice modal thicknesses in various regions of the Arctic, and can be as high as or higher than $2 \mathrm{~m}$ per winter (Haas \& Eicken, 2001). Melling \& Riedel (1996) and Strass \& Fahrbach (1998) show time series of the development of level ice drafts observed by ULS.

A comparison of summer bottom and surface melt rates between 1994 and 2007 in the Beaufort Sea and in the region of the North Pole is shown in Fig. 4.19 (Perovich et al., 2008). These observations were made from autonomous ice mass balance buoys (IMB) (RichterMenge et al., 2006) that drifted with the ice pack. These buoys are equipped with acoustic range finders placed above the ice surface and below the ice bottom, and provide information on snow accumulation and melt as well as ice growth and decay. The average annual surface melt in the Beaufort Sea is $0.64 \mathrm{~m}$, greater than near the North Pole region, where it

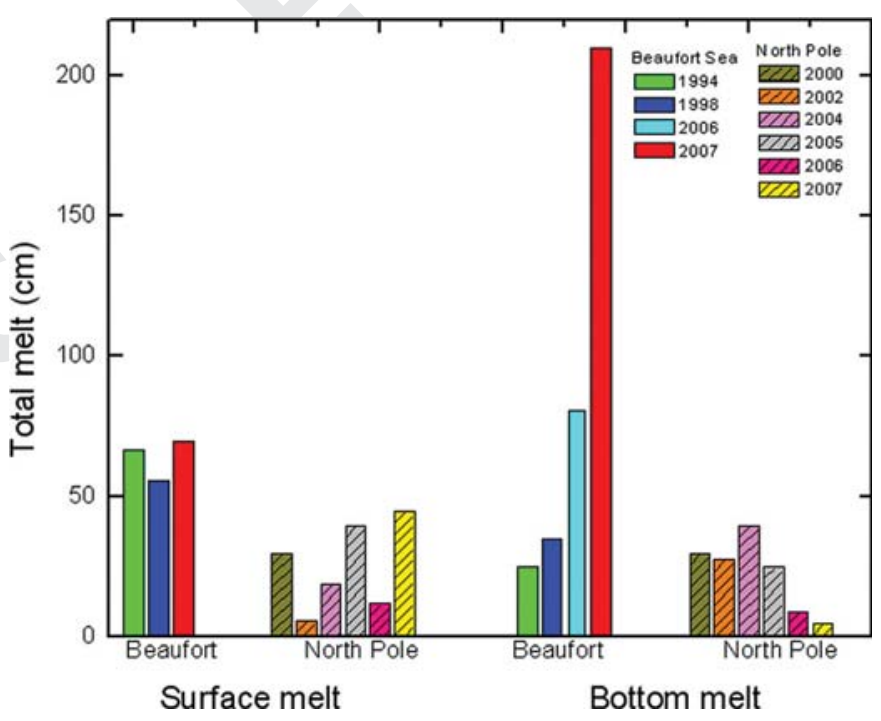

Fig. 4.19 Observations of total surface and bottom melting in different years in the Beaufort Sea and North Pole regions. From Perovich et al. (2008). 
is only $0.26 \mathrm{~m}$. These differences are primarily due to the greater incident solar radiation at the lower latitude of the Beaufort Sea. In most years, surface melt exceeds bottom melt. Both top and bottom melting exhibit interannual variability.

Despite the extreme ice cover retreat during 2007, the amount of surface melt in both regions was not significantly different in 2007 compared to earlier years. Bottom melting at the North Pole in 2007 was also comparable to earlier years. However, there was a dramatic increase in bottom melting in the Beaufort sector in 2007. This strong bottom melting was accompanied by very low ice concentrations in the region of that particular IMB (Perovich et al., 2008). Calculations indicate that this supported solar heating of the upper ocean, which was the primary source of heat for this observed enhanced bottom melting. The increase in the open water fraction resulted in a $500 \%$ positive anomaly in solar heat input to the upper ocean, triggering an ice-albedo feedback and contributing to the accelerating ice retreat. This is again an example for the close interrelationship between thermodynamic and dynamic processes. The strong bottom melt was primarily triggered by dynamically induced reductions in ice concentration. Only then could the thermodynamic ice-albedo feedback become efficient.

Haas et al. (2008c) have studied the seasonal development of surface melting in the Weddell Sea. During a 5-week drift phase as part of the Ice Station Polarstern (ISPOL) project of the German icebreaker RV Polarstern in December 2004 (Hellmer et al., 2006), snow and ice thickness changes were measured to obtain similar data as was previously available from the Arctic. However, during the observation period, there was hardly any thinning of the ice, and the originally $0.2-0.5 \mathrm{~m}$ thick snow thinned only by $0.2 \mathrm{~m}$. This is remarkable when compared with conditions in the Arctic, where the strongest surface ablation is observed during the corresponding month of June (Perovich et al., 2003), and at much higher latitudes $\left(77^{\circ} \mathrm{N}\right)$ than where the ISPOL measurements were made $\left(67^{\circ} \mathrm{S}\right)$. Overall, the slow melting rates observed during ISPOL are one reason for the general absence of melt ponds on Antarctic sea ice. They are caused by the special climatic conditions dominated by the cold Antarctic continent and the rareness of events of warm air advection from the North. Andreas and Ackley (1982), Nicolaus et al. (2006) and Vihma et al. (2009) show observations and calculations of the surface heat balance of Antarctic sea ice, and demonstrate the importance of upward turbulent heat fluxes as the dominant component for the prevention of strong surface melt.

\subsection{Conclusion and outlook}

This chapter has shown that the sea ice thickness distribution is a result of complicated thermodynamic and dynamic processes, which can also be closely interacting. There are many feedbacks involved in changes of ice thickness, and therefore the reasons for observed changes are not always clear at first sight. The deviations between climate predictions and observed changes are largely due to an under-representation of these processes in the models. Ice thickness research requires multidisciplinary approaches including model, field and remote-sensing studies.

Field studies are always limited by their restricted spatial and temporal coverage. This can be partially compensated by satellite measurements, which can also provide information on the regional redistribution of ice thickness. Completely new insights have 
now been possible with laser and radar altimetry data of ICESat, and ERS and Envisat, respectively. These showed the potential, but also the uncertainties of those measurements. Another milestone will be reached with the dedicated CryoSat mission. However, there is an urgent need to validate those satellite data, and to improve auxiliary data, particularly of sea surface height and snow thickness and density. Accurate and extensive underwater, airborne and in situ measurements are required for this validation. At present, satellite measurements are rather experimental than operational, and therefore their continuity is not guaranteed.

The optimum ice thickness observing system would therefore consist of a hierarchy of measurements at different scales and with different accuracies: ULS moorings at key sites like the big flux gates can provide continuous but local observations. These can be complemented by airborne surveys or underwater AUV measurements between mooring sites or along other transects to provide information on possible thickness gradients, which is required to estimate ice volume fluxes. Airborne campaigns or icebreaker cruises should also provide opportunities for extensive in situ measurements of snow thickness and density, and for a few validation measurements with the highest accuracy. On much larger scales, but probably with less accuracy, satellites would provide continuous and Arcticwide data, whose uncertainty could nevertheless be reduced by means of the validation measurements.

Another problem of validation is the comparability among all data sets, as they obtain thicknesses with different spatial resolution, and with varying accuracy over different thickness classes. Cross-calibrations are urgently required between EM and ULS measurements to provide a broad statistical database for comparison and to be able to develop correction functions for various ice types and conditions. Both methods are complementary, as they obtain their most accurate estimates either for level or for deformed ice. Few approaches have already been made, but a proper analysis has not been successful due to technical and/ or weather problems. Similarly, although airborne EM measurements might provide the best compromise between ease of use and accuracy, their range is limited so far. The recent PoleAirship project of French explorer Jean-Louis Etienne tried to use an airship as a potential alternative platform for Arctic-wide EM measurements, but failed due to an airship crash during test flights in southern France. A hovercraft is now under development for Arcticwide operations, which is also equipped with an EM thickness system. However, it too has some range issues to solve. The ultimate platform might be the Basler BT67 airplane of the German Alfred Wegener Institute. This plane can operate an EM-bird, and a first Arctic survey is planned for April 2009.

The examples in this book were mostly of large scales and from the central Arctic Ocean, as they had primarily been motivated by climate research aspects. However, shrinking and thinning sea ice has also fundamental consequences for the eco- and human systems of the Arctic. The ice is an important habitat and hunting and resting platform for a wide variety of organisms including Polar bears. However, it is also used by the human population of the Arctic for travel and hunting. On the contrary, it is an obstacle for shipping and offshore operations in polar waters. An understanding of short- and long-term ice thickness changes is required for these activities as well. It might even be more difficult to provide the proper thickness measurements and observation strategies, as most problems are of a local nature, and require continuous and small-scale measurements, and often fewer resources may be available for individual sites (Haas \& Druckenmiller, 2009). 


\section{References}

Anderson, W.L. (1979) Computer Program. Numerical integration of related Hankel transforms of orders 0 and 1 by adaptive digital filtering. Geophysics, 44, 1287-1305.

Andreas, E.L. \& Ackley, S.F. (1982) On the differences in ablation seasons of Arctic and Antarctic sea ice. Journal of Atmospheric Science, 39, 440-447.

Barry, R.G., Serreze, M.C., Maslanik, J.A. \& Preller, R.H. (1993) The Arctic sea ice climate system: observations and modeling. Reviews of Geophysics, 31, 397-422.

Bourke, R.H. \& Garrett, R.P. (1987) Sea ice thickness distribution in the Arctic Ocean. Cold Regions Science and Technology, 13, 259-280.

Colony, R. \& Thorndike, A.S. (1984) An estimate of the mean field of Arctic sea ice motion. Journal of Geophysical Research, 89, 10623-10629.

Coon, M.D. (1980) A review of AIDJEX modelling. In: Sea Ice Processes and Models (Ed. R.S. Pritchard), pp. 12-27. University of Washington Press, Seattle, Washington.

Dowdeswell, J.A., Evans, J., Mugford, R. et al. (2008) Autonomous underwater vehicles (AUVs) and investigations of the ice-ocean interface: deploying the Autosub AUV in Antarctic and Arctic waters. Journal of Glaciology, 54, 661-672.

Eicken, H., Tucker, W.B. \& Perovich, D.K. (2001) Indirect measurements of the mass balance of summer Arctic sea ice with an electromagnetic induction technique. Annals of Glaciology, 33, 194-200.

Eicken, H., Grenfell, T.C., Perovich, D.K., Richter-Menge, J.A. \& Frey, K. (2004) Hydraulic controls of summer Arctic pack ice albedo. Journal of Geophysical Research, 109, C08007, 10.1029/2003JC001989.

Gerdes, R. \& Köberle, C. (2007) Comparison of Arctic sea ice thickness variability in IPCC climate of the 20th century experiments and in ocean-sea ice hindcasts. Journal of Geophysical Research, 112, C04S01, 10.1029/2006JC003616.

Giles, K.A., Laxon, S.W. \& Worby, A.P. (2008) Antarctic sea ice elevation from satellite radar altimetry. Geophysical Research Letters, 35, L03503, doi:10.1029/2007GL031572.

Haas, C. (1998) Evaluation of ship-based electromagnetic-inductive thickness measurements of summer sea ice in the Bellingshausen and Amundsen Sea. Cold Regions Science and Technology, 27, 1-16.

Haas, C. \& Druckenmiller, M. (2009) Ice thickness and roughness measurements. In: Sea Ice Handbook. (Eds. Eicken, H., Gradinger, R., Salganek, M., Shirasawa, K., Perovich, D. \& Lepparanta, M.). University of Alaska Fairbanks Press.

Haas, C. \& Eicken, H. (2001) Interannual variability of summer sea ice thickness in the Siberian and Central Arctic under different atmospheric circulation regimes. Journal of Geophysical Research, 106, 4449-4462.

Haas, C. \& Jochmann, P. (2003) Continuous EM and ULS thickness profiling in support of ice force measurements. In: Proceedings of the 17th International Conference on Port and Ocean Engineering under Arctic Conditions, POAC '03, Trondheim, Norway, Vol. 2 (Eds. S. Loeset, B. Bonnemaire \& M. Bjerkas), pp. 849-856. Department of Civil and Transport Engineering, Norwegian University of Science and Technology NTNU, Trondheim, Norway.

Haas, C., Gerland, S., Eicken, H. \& Miller, H. (1997) Comparison of sea ice thickness measurements under summer and winter conditions in the Arctic using a small electromagnetic induction device. Geophysics, 62, 749-757.

Haas, C., Liu, Q. \& Martin, T. (1999a) Retrieval of Antarctic sea ice pressure ridge frequencies from ERS SAR imagery by means of in-situ laser profiling and usage of a neural network. International Journal of Remote Sensing, 2, 3111-3123.

Haas, C., Rupp, K.-H. \& Uuskallio, A. (1999b) Comparison of along track EM ice thickness profiles with ship performance data. In: Proceedings of the 15th International Conference on Port and Ocean Engineering Under Arctic Conditions (POAC '99), Espoo, Finland, August 23-27, Vol. 1 
(Eds. J. Tuhkuri \& K. Riska), pp. 343-353. Helsinki University of Technology, Ship Laboratory, Helsinki, Finland.

Haas, C., Hendricks, S. \& Doble, M. (2006) Comparison of the sea ice thickness distribution in the Lincoln Sea and adjacent Arctic Ocean in 2004 and 2005. Annals of Glaciology, 44, 247-252.

Haas, C., Pfaffling, A., Hendricks, S., Rabenstein, L., Etienne, J.-L. \& Rigor, I. (2008a) Reduced ice thickness in Arctic Transpolar Drift favors rapid ice retreat. Geophysical Research Letters, 35, L17501, 10.1029/2008GL034457.

Haas, C., Lobach, J., Hendricks, S., Rabenstein, L. \& Pfaffling, A. (2008b) Helicopter-borne measurements of sea ice thickness, using a small and lightweight, digital EM system. Journal of Applied Geophysics, 10.1016/j.jappgeo.2008.05.005.

Haas, C., Nicolaus, M., Willmes, S., Worby, A. \& Flinspach, D. (2008c) Sea ice and snow thickness and physical properties of an ice floe in the western Weddell Sea and their changes during spring warming. Deep-Sea Research Part II, 55, 963-974.

Harms, S., Fahrbach, E. \& Strass, V.H. (2001) Sea ice transports in the Weddell Sea. Journal of Geophysical Research, 106, 9057-9073.

Hellmer, H.H., Dieckmann, G.S., Haas, C. \& Schröder, M. (2006) Sea ice feedbacks observed in western Weddell Sea. EOS Transactions, 87, 173.

Hibler, W.D., III (1979) A dynamic thermodynamic sea ice model. Journal of Physical Oceanography, 7, 987-1015.

Holland, M.M., Bitz, C.M. \& Tremblay, B. (2006) Future abrupt reductions in the summer Arctic sea ice. Geophysical Research Letters, 33, L23503, 10.1029/2006GL028024.

Holloway, G. \& Sou, T. (2002) Has Arctic sea ice rapidly thinned? Journal of Climate, 15, 1691-1701.

Holt, B., Kanagaratnam, P., Gogineni, S.P., Ramasami, V.C., Mahoney, A. \& Lytle, V. (2008) Sea ice thickness measurements by ultrawideband penetrating radar: first results. Cold Regions Science and Technology, 10.1016/ j.coldregions.2008.04.007.

Hopkins, M.A. (1994) On the ridging of intact lead ice. Journal of Geophysical Research, 99, 16351-16360.

Hurrel, J.W. (1995) Decadal trends in the North Atlantic Oscillation: regional temperatures and precipitation. Science, 269, 676-679.

Hvidegaard, S.M. \& Forsberg, R. (2002) Sea ice thickness from airborne laser altimetry over the Arctic Ocean north of Greenland. Geophysical Research Letters, 29, 1952, 10.1029/2001GL014474.

Kanagaratnam, P., Markus, T., Lytle, V., Heavey, B., Jansen, P., Prescott, G. \& Gogineni, S.P. (2007) Ultrawideband radar measurements of thickness of snow over sea ice. IEEE Transactions on Geoscience and Remote Sensing, 45, 2715-2724.

Karvonen, J., Similä, M., Haapala, J., Haas, C. \& Mäkynen, M. (2004) Comparison of SAR data and operational sea ice products to EM ice thickness measurements in the Baltic Sea. Proceedings, IEEE International Geoscience and Remote Sensing Symposium (IGARSS'04), Anchorage, Alaska. (IGARSS), 5, 3021-3024.

Köberle, C. \& Gerdes, R. (2003) Mechanisms determining the variability of Arctic sea ice conditions and export. Journal of Climate, 16, 2843-2858.

Kottmeier, C., Olf, J., Frieden, W. \& Roth, R. (1992) Wind forcing and ice motion in the Weddell Sea region. Journal of Geophysical Research, 97, 20373-20382.

Kovacs, A. \& Holladay, J.S. (1990) Sea ice thickness measurements using a small airborne electromagnetic sounding system. Geophysics, 55, 1327-1337.

Kovacs, A., Valleau, N.C. \& Holladay, J.S. (1987) Airborne electromagnetic sounding of sea ice thickness and subice bathymetry. Cold Regions Science and Technology, 14, 289-311.

Kovacs, A., Holladay, J.S. \& Bergeron, C.J.J. (1995) The footprint/altitude ratio for helicopter electromagnetic sounding of sea ice thickness: comparison of theoretical and field estimates. Geophysics, 60, 374-380.

Kwok, R. (2004) Annual cycles of multiyear sea ice coverage of the Arctic Ocean: 1999-2003. Journal of Geophysical Research, 109, C11004, 10.1029/2003JC002238. 
Kwok, R. (2007) Near zero replenishment of the Arctic multiyear sea ice cover at the end of 2005 summer. Geophysics Research Letters, 34, L05501, 10.1029/2006GL028737.

Kwok, R. \& Cunningham, G.F. (2008) ICESat over Arctic sea ice: estimation of snow depth and ice thickness. Journal of Geophysical Research, 113, C08010, 10.1029/2008JC004753.

Kwok, R., Cunningham, G.F. \& Yueh, S. (1999) Area balance of the Arctic Ocean perennial ice zone: October 1996-April 1997. Journal of Geophysical Research, 104, 25747-25759.

Kwok, R., Zwally, H.J. \& Yi, D. (2004) ICESat observations of Arctic sea ice: a first look. Geophysical Research Letters, 31, L16401, 10.1029/2004GL020309.

Kwok, R., Cunningham, G.F., Zwally, H.J. \& Yi, D. (2006) ICESat over Arctic sea ice: interpretation of altimetric and reflectivity profiles. Journal of Geophysical Research, 111, C06006, 10.1029/2005JC003175.

Kwok, R., Comiso, J.C., Martin, S. \& Drucker, R. (2007) Ross Sea polynyas: response of ice concentration retrievals to large areas of thin ice. Journal of Geophysical Research, 112, C12012, 10.1029/2006JC003967.

Lange, M.A. \& Eicken, H. (1991) The sea ice thickness distribution in the northwestern Weddell Sea. Journal of Geophysical Research, 96, 4821-4837.

Laxon, S., Peacock, N. \& Smith, D. (2003) High interannual variability of sea ice thickness in the Arctic region. Nature, 425, 947-950, 10.1038/nature02050.

Lensu, M. \& Haas, C. (1998) Comparison of ice thickness from ship based video and field data. In: Ice in Surface Waters (Ed. H.T. Shen), pp. 225-230. Proceedings of the 14th International Symposium on Ice, Potsdam, New York. Balkema, Rotterdam.

Liu, G. \& Becker, A. (1990) Two-dimensional mapping of sea ice keels with airborne electromagnetic. Geophysics, 55, 239-248.

Martin, S., Drucker, R., Kwok, R. \& Holt, B. (2004) Estimation of the thin ice thickness and heat flux for the Chukchi Sea Alaskan coast polynya from Special Sensor Microwave/Imager data, 19902001. Journal of Geophysical Research, 109, C10012, 10.1029/2004JC002428.

Maslanik, J.A., Fowler, C., Stroeve, J., Drobot, S., Zwally, J., Yi, D. \& Emery, W. (2007) A younger, thinner Arctic ice cover: Increased potential for rapid, extensive sea ice loss. Geophysical Research Letters, 34, L24501, 10.1029/2007GL032043.

Massom, R.A., Eicken, H., Haas, C. et al. (2001) Snow on Antarctic Sea Ice. Reviews of Geophysics, 39, 413-445.

Melling, H. \& Riedel, D.A. (1995) The underside topography of sea ice over the continental shelf of the Beaufort Sea in the winter of 1990. Journal of Geophysical Research, 100, 13,641-13,653.

Melling, H. \& Riedel, D.A. (1996) Development of seasonal pack ice in the Beaufort Sea during the winter of 1991-1992: a view from below. Journal of Geophysical Research, 101, 11,975-11,991.

Melling, H. \& Riedel, D.A. (2004) Draft and movement of pack ice in the Beaufort Sea: a time-series presentation April 1990-August 1999. Canadian Technical Reports on Hydrographic Oceanic Science, 238, $24 \mathrm{pp}$.

Melling, H., Riedel, D.A. \& Gedalof, Z. (2005) Trends in the draft and extent of seasonal pack ice, Canadian Beaufort Sea. Geophysical Research Letters, 32, L24501, 10.1029/2005GL024483.

Multala, J., Hautaniemi, H., Oksama, M., Leppäranta, M., Haapala, J., Herlevi, A., Riska, K. \& Lensu, M. (1996) An airborne electromagnetic system on a fixed wing aircraft for sea ice thickness mapping. Cold Regions Science and Technology, 24, 355-373.

Nghiem, S.V., Rigor, I.G., Perovich, D.K., Clemente-Colón, P., Weatherly, J.W. \& Neumann, G. (2007) Rapid reduction of Arctic perennial sea ice. Geophysical Research Letters, 34, L19504, 10.1029/2007GL031138.

Nicolaus, M., Haas, C., Bareiss, J. \& Willmes, S. (2006) A model study of differences of snow thinning on Arctic and Antarctic first-year sea ice during spring and summer. Annals of Glaciology, 44, 146-153.

Perovich, D.K., Grenfell, T.C., Richter-Menge, J.A., Light, B., Tucker III, W.B. \& Eicken, H. (2003) Thin and thinner: sea ice mass balance measurements during SHEBA. Journal of Geophysical Research, 108, 8050, 10.1029/2001JC001079. 
Perovich, D.K., Richter-Menge, J.A., Jones, K.F. \& Light, B. (2008) Sunlight, water, and ice: extreme Arctic sea ice melt during the summer of 2007. Geophysical Research Letters, 35, L11501, 10.1029/2008GL034007.

Peterson, I.K., Prinsenberg, S.J. \& Holladay, J.S. (2008) Observations of sea ice thickness, surface roughness and ice motion in Amundsen Gulf. Journal of Geophysical Research, 113, C06016, 10.1029/2007JC004456.

Pfaffling, A., Haas, C. \& Reid, J.E. (2007) A direct helicopter EM sea ice thickness inversion, assessed with synthetic and field data. Geophysics, 72, F127- F137.

Prinsenberg, S.J. \& Holladay, J.S. (1993) Using air-borne electromagnetic ice thickness sensor to validate remotely sensed marginal ice zone properties. In: Proceedings of the 12th International Conference on Port and Ocean Engineering under Arctic Conditions (POAC '93), Hamburg, 1993, Vol. 2 (Eds. J. Schwarz \& K.V. Evers), pp. 936-948. Hamburgische Schiffbau-Versuchsanstalt, Hamburg.

Prinsenberg, S.J., Holladay, J.S. \& Lee, J. (2002) Measuring ice thickness with EISFlowTM, a fixedmounted helicopter electromagnetic-laser system. In: Proceedings of the Twelfth (2002) International Offshore and Polar Engineering Conference May 26-31, 2002, Vol. 1, pp. 737-740, Kitakyushu, Japan.

Proshutinsky, A.Y. \& Johnson, M.A. (1997) Two circulation regimes of the wind-driven Arctic Ocean. Journal of Geophysical Research, 102, 12493-12514.

Reid, J.E., Worby, A.P., Vrbancich, J. \& Munro, A.I.S (2003) Shipborne electromagnetic measurements of Antarctic sea ice thickness. Geophysics, 68, 1537-1546, 10.1190/1.1620627.

Reid, J.E., Pfaffling, A. \& Vrbancich, J. (2006) Airborne electromagnetic footprints in 1D earths. Geophysics, 71, G63-G72.

Richter-Menge, J.A., Perovich, D.K., Elder, B.C., Claffey, K., Rigor, I. \& Ortmeyer, M. (2006) Ice mass balance buoys: a tool for measuring and attributing changes in the thickness of the Arctic sea ice cover. Annals of Glaciology, 44, 205-210.

Rigor, I.G. \& Wallace, J.M. (2004) Variations in the age of Arctic sea ice and summer sea ice extent. Geophysical Research Letters, 31, L09401, 10.1029/2004GL019492.

Rinke, A., Gerdes, R., Dethloff, K. et al. (2003) A case study of the anomalous Arctic sea ice conditions during 1990: insights from coupled and uncoupled regional climate model simulations. Journal of Geophysical Research, 108, 4275, 10.1029/2002JD003146.

Rothrock, D.A. \& Wensnahan, M. (2007) The accuracy of sea ice drafts measured from U.S. Navy submarines. Journal of Atmospheric and Oceanic Technology, 10.1175/JTECH2097.1.

Rothrock, D.A. \& Zhang, J. (2005) Arctic Ocean sea ice volume: what explains its recent depletion? Journal of Geophysical Research, 110, C01002, 10.1029/2004JC002282.

Rothrock, D.A., Yu, Y. \& Maykut, G.A. (1999) Thinning of the Arctic sea ice cover. Geophysical Research Letters, 26, 3469-3472.

Rothrock, D.A., Percival, D.B. \& Wensnahan, M. (2008) The decline in arctic sea ice thickness: separating the spatial, annual, and interannual variability in a quarter century of submarine data. Journal of Geophysical Research, 113, C05003, 10.1029/2007JC004252.

Saldern, C., von, Haas, C. \& Dierking, W.(2006) Parameterisation of Arctic sea ice surface roughness for application in ice type classification. Annals of Glaciology, 44, 224-230.

Serreze, M.C., McLaren, A.S. \& Barry, R.G. (1989) Seasonal variations of sea ice motion in the Transpolar Drift Stream. Geophysical Research Letters, 16, 811-814.

Strass, V.H. \& Fahrbach, E. (1998) Temporal and regional variation of sea ice draft and coverage in the Weddell Sea obtained from Upward Looking Sonars. In: Antarctic Sea Ice: Physical Processes, Interactions and Variability (Ed. M.O. Jeffries). American Geophysical Union, Washington, D.C. Antarctic Research Series, 74, 123-140.

Stroeve, J., Holland, M.M., Meier, W., Scambos, T. \& Serreze, M. (2007) Arctic sea ice decline: faster than forecast. Geophysical Research Letters, 34, L09501, 10.1029/2007GL029703. 
Stroeve, J., Serreze, M., Drobot, S. et al. (2008) Arctic Sea Ice Extent Plummets in 2007. EOS Transactions American Geophysical Union, 89 (2), 13.

Thompson, D.W.J. \& Wallace, J.M. (1998) The Arctic Oscillation signature in the wintertime geopotential height and temperature fields. Geophysical Research Letters, 25, 1297-1300.

Thorndike, A.S., Rothrock, D.A., Maykut, G.A. \& Colony, R. (1975) The thickness distribution of sea ice. Journal of Geophysical Research, 80, 4501-4513.

Timmermann, R., Beckmann, A. \& Hellmer, H.H. (2002) Simulations of ice-ocean dynamics in the Weddell Sea. I: model configuration and validation. Journal of Geophysical Research, 107, 3024, 10.1029/2000JC000741.

Tucker, W.B., III, Weatherly, J.W., Eppler, D.T., Farmer, L.D. \& Bentley, D.L. (2001) Evidence for rapid thinning of sea ice in the western Arctic Ocean at the end of the 1980s. Geophysical Research Letters, 28, 2851-2854.

Uto, S., Toyota, T., Shimoda, H., Tateyama, K. \& Shirasawa, K. (2006) Ship-borne electromagnetic induction sounding of sea ice thickness in the southern Sea of Okhotsk. Annals of Glaciology, 44, $253-260$

Vihma et al. (2009) ISPOL Journal of Geophysical Research, in press.\{AQ1\}

Vinje, T., Nordlund, N. \& Kvambekk, A. (1998) Monitoring ice thickness in Fram Strait. Journal of Geophysical Research, 103, 10437-10450.

Wadhams, P. (1994) Sea ice thickness changes and their relation to climate. In: The Polar Oceans and Their Role in Shaping the Global Environment (Eds. O.M. Johannessen, R.D. Muench \& J.E. Overland). American Geophysical Union, Washington, DC. Geophysical Monograph, 85, 337-362.

Wadhams, P. \& Davis, N.R. (2000) Further evidence of ice thinning in the Arctic Ocean. Geophysical Research Letters, 27, 3973-3975.

Wadhams, P., Wilkinson, J.P. \& McPhail, S.D. (2006) A new view of the underside of Arctic sea ice. Geophysical Research Letters, 33, L04501, 10.1029/2005GL025131.

Warren, S.G., Rigor, I.G., Untersteiner, N., Radionov, V.F., Bryazgin, N.N., Aleksandrov, Y.I. \& Colony, R. (1999) Snow depth on Arctic sea ice. Journal of Climate, 12, 1814-1829.

Wingham, D.J., Phalippou, L., Mavrocordatos, C. \& Wallis, D. (2004) The mean echo and echo cross product from a beamforming interferometric altimeter and their application to elevation measurement. IEEE Transactions of Geoscience and Remote Sensing, 42, 2305-2323.

Worby, A.P., Jeffries, M.O., Weeks, W.F., Morris, K. \& Jaña, R. (1996) The thickness distribution of sea ice and snow cover during late winter in the Bellingshausen and Amundsen Seas, Antarctica. Journal of Geophysical Research, 101, 28441-28455.

Worby, A.P., Geiger, C.A., Paget, M.J., Van Woert, M.L., Ackley, S.F.\& DeLiberty, T.L. (2008) Thickness distribution of Antarctic sea ice. Journal of Geophysical Research, 113, C05S92, 10.1029/2007JC004254.

Yu, Y. \& Rothrock, D.A. (1996) Thin ice thickness from satellite thermal imagery. Journal of Geophysical Research, 101 (C11), 25,753-25,766.

Zhang, J., Rothrock, D. \& Steele, M. (2000) Recent changes in Arctic sea ice: the interplay between ice dynamics and thermodynamics. Journal of Climate, 13, 3099-3114.

Zwally, H.J., Yi, D., Kwok, R. \& Zhao, Y. (2008) ICESat measurements of sea ice freeboard and estimates of sea ice thickness in the Weddell Sea. Journal of Geophysical Research, 113, C02S15, 10.1029/2007JC004284. 
